American J. of Engineering and Applied Sciences 4 (1): 17-36, 2011

ISSN 1941-7020

(C) 2010 Science Publications

\title{
Seismic Performance Evaluation of Reinforced Concrete Moment Resisting Frames with Various Ductility in Low Seismic Zone
}

\author{
N. Choopool and V. Boonyapinyo \\ Faculty of Engineering, Thammasat University, Rangsit Campus, \\ Pathumthani, 12120, Thailand
}

\begin{abstract}
Problem statement: Bangkok, the capital of Thailand, is at moderate risk for distant earthquake due to the ability of soft soil to amplify ground motion about 3-4 times although it locates in low seismic zone. In addition, before the enforcement of seismic loading for buildings in the Ministerial Law in 2007, many existing reinforced concrete buildings in Bangkok may have been designed without consideration for seismic loading and did not incorporate the special detailing provisions that required for ductile concrete frames. Now, guidelines for seismic loading of buildings of Thailand (DPT 1302-52) have been recently improved by adopting ASCE7-05. Approach: This study is focused on the effects of the new guidelines on cost estimates and the seismic performance of a nine-story reinforced concrete apartment building with various ductility by the nonlinear static and nonlinear dynamic analyses compared with a Gravity Load Designed (GLD) building. Five selected ground motion records are investigated in the analyses. In order to examine the influence of design ductility classes, the seismic forces on moment resisting frame buildings are defined according to the newly proposed seismic specifications of Thailand with ductility from 8,5 and 3, corresponding to Special Ductile (SDF), Intermediate Ductile (IDF) and Ordinary Ductile (ODF) frames, respectively. The various frames are assumed to have collapsed if the local drift exceed of 3, 2.5, 2 and $1 \%$ for SDF, IDF, ODF and GLD, respectively. Results: SDF is more ductile than that of ODF, however, the strength of SDF is less than ODF. For inelastic designs, SDF decreases stiffness and increases deflection of structures. As for the effect on cost estimates, ODF is the most expensive among ODF, IDF and SDF. Costs of SDF and IDF in Bangkok are quite similar. The study found that the average PGAs for the failure state for SDF, IDF, ODF and GLD are 0.76, 0.60, 0.50 and $0.29 \mathrm{~g}$, respectively. Moreover, for the failure state of GLD with volumetric ratio of horizontal confinement within joint panel less than 0.003 , the average PGA is only $0.15 \mathrm{~g}$. Conclusion/Recommendations: These various frame designs are predicted to just achieve the Immediate Occupancy (IO) performance level. The results also indicate that all frames including GLD are able to withstand a design earthquake. The SDF and IDF are the two best options in consideration of cost and seismic performance.
\end{abstract}

Key words: Seismic evaluation, pushover analysis, nonlinear dynamic analysis, reinforced-concrete buildings

\section{INTRODUCTION}

Bangkok, the capital of Thailand, is at moderate risk from a distant earthquake due to the ability of soft soil to amplify ground motion about 3-4 times (Warnitchai and Sangarayakul, 2000). In addition, before the enforcement of seismic loading for buildings in the Thai Ministerial Law in 2007, many existing reinforced concrete buildings in Bangkok may have been designed without consideration for seismic loading and did not incorporate the special detailing provisions that required for ductile concrete frames (Lukkunaprasit, 2001; Kiattivisanchai, 2001).

The changes in the current code for seismic design of buildings in Thailand are being made to achieve better seismic performance of buildings. According to the current code, engineers have different options for the capacity design of reinforced concrete frames. The first option is to design the ordinary ductile frame $(\mathrm{R}=3)$ without making special provisions for capacity design and good detailing. The second option is to design an intermediate ductile frame

Corresponding Author: Virote Boonyapinyo, Faculty of Engineering, Thammasat University, Rangsit Campus, Pathumthani, 12120, Thailand Tel: +662-564-3001 Fax: +662-564-3010 
$(\mathrm{R}=5)$ which involves designing for three-fifths of the seismic lateral load compared with that of the ordinary ductile frame with limited detailing provisions to ensure intermediate 2 ductile behavior. The last option is to design the special ductile frame $(\mathrm{R}=8)$, which involves designing for three-eighths of the seismic lateral load compared with that of the ordinary ductile frame with special design and detailing provisions to ensure special ductile behavior. By allowing such choices, the code implies that three types of frames will provide equivalent seismic performance under a design level earthquake disturbance. The seismic design loads and the level of seismic reinforcement detailing incorporated in a reinforced concrete moment resisting frame depend on its available ductility capacity.

Presently, there are two methods for investigating inelastic seismic performance. One is the nonlinear time history analysis and another is nonlinear static analysis called "pushover analysis". The static pushover analysis can also be divided into two methods. One is based on the first-mode pushover analysis (ATC, 1996; FEMA NEHRP, 1997; Pessiki et al., 1990). The other is based on the Modal Pushover Analysis (MPA) where higher mode effects are taken into account (Chopra and Goel, 2002). In the literature, there are many studies related to the seismic evaluation. For example Chopra and Goel (2002) proposed a modal pushover analysis to include contribution of higher modes. Kunnath and Kalkan (2007) compared to non-linear time history analyses, pushover methods tend to underestimate demand at the upper levels signifying the relevance of high mode participation in mid to high rise structures. Chopra and Goel (1999) proposed a method to estimate a capacity demand diagram and used the constant ductility design spectra as an improvement over the capacity spectrum method in ATC (1996). Fajfar (2000) proposed a method formulated in the acceleration-displacement format where inelastic spectra were applied. This feature represents the major difference with respect to the capacity spectrum method. Demand quantities can be obtained without iteration.

Now, the guidelines for seismic loading of buildings have been recently improved adopting ASCE (2005). The newly proposed seismic specifications of Thailand (DPT, 2009) are modern and compatible with the codes in other seismic countries of the world and will be periodically updated to reflect progress of knowledge in the field of earthquake resistant design. Therefore, the evaluation of seismic capacity of buildings in Thailand according to the newly proposed seismic specification of Thailand would be of interest.
In this study, buildings designed under seismic effects according to the newly proposed seismic specification of Thailand and the gravity load designed buildings are investigated. For buildings designed under seismic effect, analytical investigation is conducted to evaluate the performance of frame buildings under response modification factors $(\mathrm{R})$ and seismic ground motion values such as soil type classifications $\left(\mathrm{F}_{\mathrm{a}}\right)$ and spectral response acceleration parameters $\left(\mathrm{S}_{\mathrm{S}}\right)$ by the nonlinear static analysis and nonlinear dynamic analysis. The seismic forces to frame buildings are defined according to the newly proposed seismic specification of Thailand with ductility from 8,5 and 3 in order to examine the influence of the design ductility classes as moment resisting frames with Special Ductile (SDF), Intermediate Ductile (IDF) and Ordinary Ductile (ODF) frames, respectively. These structures were designed and detailed in accordance with provisions of UBC (1997) and of DPT (2007) so that they can be representative of the ordinary ductile, intermediate ductile, special ductile frames. For Gravity Load Designed frame (GLD), the seismic performance of a reinforced-concrete building designed without any consideration on seismic effect is evaluated and compared.

Nonlinear analysis procedure: Nonlinear analysis procedure consists of both nonlinear static and nonlinear dynamic analyses. Nonlinear static analysis is known as pushover analysis. Nonlinear dynamic analysis provides a more accurate estimate of the dynamic response of the structure. Both of them are used to investigate the seismic performance of reinforced concrete structures.

Pushover Analysis (PA): This method consists of lateral static loading to push the structures in one direction. The load is increased until a target displacement is reached (ATC, 1996). There are many loading patterns that used for analysis and recommended in FEMA NEHRP (1997). The analysis cannot accurately account for changes in dynamic response as the stiffness degradation or higher mode effect (Seneviratna and Krawinkler, 1997). The capacity curve is constructed in order to investigate the capacity of structures. It represents the first mode response.

Modal Pushover Analysis (MPA): In the MPA procedure (Chopra, 2007), the peak response of the building to $P_{\text {eff }, \mathrm{n}}(t)=-S_{n} \ddot{u} g(t)$ the $n^{\text {th }}$ mode component of effective force, is determined by a nonlinear static or pushover analysis. Defined by $\mathrm{s}=\mathrm{mi}$, the spatial 
(height-wise) distribution of forces can be expanded into its modal components $\left(s_{n}\right) ; s_{n}=\Gamma_{n} m \phi_{n}$ where $\phi_{n}$ is the $\mathrm{n}^{\text {th }}$ mode and $\Gamma_{\mathrm{n}}=\phi_{\mathrm{n}}^{\mathrm{T}} \mathrm{mi} / \phi_{\mathrm{n}}^{\mathrm{T}} \mathrm{m} \phi \mathrm{j}$.

The peak demands due to these modal components of forces are then combined by an appropriate modal combination rule. The steps are summarized as a series used to estimate the peak inelastic response of higher modes of vibration.

Capacity Spectrum Method (CSM) in ATC-40: In this study the capacity spectrum method is the method used in procedure B of ATC (1996). The evaluation of seismic performance of structures is necessary to determine the ductility and total viscous damping. Typically, the capacity curve will intersect the demand curves corresponding to several viscous damping ratios. Each point on the capacity curve can be associated with an equivalent viscous damping ratio and natural period. The point at which the capacity curve intersects a demand curve associated with the same viscous damping ratio is the performance point which defines the spectral displacement demand.

Inelastic Demand Diagram Method (IDDM): The inelastic response spectrums for ESDOF were generated assuming elastoplastic systems. The demand spectrums for $5 \%$ damped ranging the ductility factor ( $\mu$ ) from 1-4 subjected to a suite of record ground motions used for the evaluation. Chopra and Goel (1999) presented the performance procedure by graphical method with iteration. The static equivalent spectral displacement and spectral acceleration obtained from the pushover analysis as shown in Eq. 1 and 2:

$$
\begin{aligned}
& \mathrm{S}_{\mathrm{a}}=\frac{\mathrm{V} / \mathrm{W}}{\mathrm{a}_{1}} \\
& \mathrm{~S}_{\mathrm{d}}=\frac{\Delta_{\text {roof }}}{\mathrm{PF}_{1} \phi_{\text {lroof }}}
\end{aligned}
$$

Where:

$$
\begin{array}{ll}
\mathrm{V} & =\text { The base shear from pushover analysis } \\
\mathrm{W} & \text { The building dead weight } \\
= & \text { The modal mass coefficient for the first } \\
& \text { natural mode } \\
\alpha_{1} & \text { The lateral roof displacement } \\
= & \text { Modal participation factor for the first } \\
& \text { natural mode } \\
\Delta_{\text {roof }} & \text { The amplitude of the first natural mode } \\
\mathrm{PF}_{1} & \text { of the building } \\
\phi_{1} & \begin{array}{l}
\text { Equivalent spectral displacement and } \\
\text { spectral acceleration estimated by the } \\
\mathrm{S}_{\mathrm{d}} \text { and } \mathrm{S}_{\mathrm{a}}=
\end{array}
\end{array}
$$

When both capacity and demand diagrams are plotted in the Acceleration- Displacement format, the yielding branch of the capacity diagram intersects the demand curves for several ductility factor $(\mu)$ values. The intersection between capacity and demand spectrum having the same ductility factor is the performance point. The system ductility demand is estimated by the ratio of yield displacement in capacity spectrum to inelastic maximum displacement in the performance point.

Fajfar (2000) presented the intersection of the radial line corresponding to the elastic period of the idealized bilinear system, $\mathrm{T}^{*}$ with the elastic demand spectrum, $\mathrm{S}_{\mathrm{ae}}$ defines the acceleration demand required for elastic behavior and the corresponding elastic displacement demand. The yield acceleration, $\mathrm{S}_{\mathrm{ay}}$ represents both the acceleration demand and the capacity of inelastic system. The reduction factor, $R_{\mu}$ can be determined as the ratio between the accelerations corresponding to the elastic and inelastic system:

$\mathrm{R}_{\mu}=\frac{\mathrm{S}_{\mathrm{ac}}\left(\mathrm{T}^{*}\right)}{\mathrm{S}_{\mathrm{ay}}}$

If the elastic period, $\mathrm{T}^{*}$, is larger than or equal to $\mathrm{T}_{\mathrm{c}}$; the transition period where the constant acceleration segment of the response spectrum passes to the constant velocity segment of the spectrum, the inelastic displacement demand, $S_{d}$ is equal to the elastic displacement demand $S_{\text {de }}$. The ductility demand, define as $\mu=S_{d} / D_{Y}^{*}$ is equal to $R_{\mu}$ :

$\mathrm{S}_{\mathrm{d}}=\mathrm{S}_{\mathrm{de}}\left(\mathrm{T}^{*}\right) \mathrm{T}^{*} \geq \mathrm{T}_{\mathrm{c}}$

$\mu=\mathrm{R}_{\mu}$

If the elastic period, $\mathrm{T}^{*}$, is smaller than $\mathrm{T}_{\mathrm{c}}$, the ductility demand can be calculated as shown in Eq. 6:

$\mu=\left(\mathrm{R}_{\mu}-1\right) \frac{\mathrm{T}_{\mathrm{c}}}{\mathrm{T}^{*}}+1 \mathrm{~T}^{*}<\mathrm{T}_{\mathrm{c}}$

The displacement demand can be determined:

$\mathrm{S}_{\mathrm{d}}=\mu \mathrm{D}_{\mathrm{y}}^{*}$

The intersection of the radial line corresponding to the elastic stiffness of the idealized bilinear system and the elastic demand spectrum defines the strength required for elastic behavior and the corresponding elastic displacement demand. 
Nonlinear Time History Analysis (NTHA): The displacement demand of structures can be accurately computed through a time history analysis. It is a step by-step analysis of the dynamical response of a structure to a specified loading that may vary with time. A suitable model and a suite of appropriate ground motions are selected. The dynamic equilibrium equations to be solved are given by:

$m \ddot{u}(t)+c \dot{u}(t)+k u(t)=r(t)$

Where:

$\begin{aligned} \mathrm{k} & =\text { The stiffness matrix } \\ \mathrm{c} & =\text { The damping matrix } \\ \mathrm{m} & =\text { The diagonal mass matrix } \\ \ddot{\mathrm{u}}, \dot{\mathrm{u}}, \mathrm{u} & =\text { The displacement, velocities and accelerations } \\ & \text { of the structure } \\ \mathrm{r} \quad & =\text { The applied load }\end{aligned}$

The nonlinear response of structures is very sensitive to the structural modeling and ground motion characteristic. Therefore, a set of representative ground motion records that accounts for uncertainties and differences in severity, frequency characteristics has to be used to predict the possible deformation modes of the structures for seismic performance evaluation purposes.

Structural modeling: A finite element model of buildings by SAP2000 (2000) that can simulate nonlinear behavior is formulated by considering several important effects such as p-delta, masonry infill walls, soil-structure interaction and beam-column joints.

Masonry infill wall model: The masonry infill wall was considered to account for the effect of nonstructural elements in buildings. The masonry infill wall is modeled as equivalent struts according to FEMA NEHRP (1997). These properties with a thickness $0.065 \mathrm{~m}$, compression strength of $4 \mathrm{MPa}$ and elastic young's modulus of 1300 have been used in this study. It increase the lateral stiffness of the buildings but do not increase the lateral ultimate strength of the buildings. More details are given by Choopool (2010), among others.

Joint model: Beam-column joint Fig. 1 that can be considered rigid zones with joint failure due to poor detailing of joints, shear failure in columns and beams. More details are given by Choopool (2010), among others.

Foundation model: Behavior of foundation components and effects of soil-structure interaction were investigated due to most buildings in Bangkok are

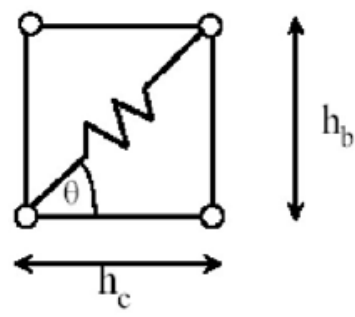

Fig. 1: Rigid beam-column joint modeling

constructed by using deep foundations. Soil-structure interaction can lead to modification of building response. Soil flexibility results in period elongation and damping increase. The main relevant impacts are to modify the overall lateral displacement and to provide additional flexibility at the base level that may relieve inelastic deformation demands in the superstructure.

In this study, the subgrade-reaction model originally proposed by Winkler (1967) which can be represented by a series of uncoupled lateral and axial springs simulating soil-pile interaction used in order to model the behavior of foundations. The force deformation relation of the soil spring element is approximated by an elastic-perfectly plastic model that has an initial stiffness equal to horizontal modulus of subgrade reaction and the maximum force equal to the ultimate soil resistance. Details for the Winkler model are given by Boonyapinyo et al. (2006), among others.

The effect of foundation stiffness on the capacity of the building was also evaluated. At the same load level, the roof displacement of flexible support is slightly higher than of fixed support. This is because the flexible support allows the building to rotate and translate resulting in additional displacement at the roof. However, for this building, the pile foundation was relatively stiff and did not significant affect the building capacity and response. More details are given by Choopool (2010).

Initial stiffness: The reduced initial flexural and shear stiffness values are considered according to ATC (1996). The reduced values for flexural stiffness are $0.50 \mathrm{I}_{\mathrm{g}}$ for beams and $0.70 \mathrm{I}_{\mathrm{g}}$ for columns. The reduced value for shear stiffness is $0.40 \mathrm{~A}_{\mathrm{w}}$ for columns and beams. $I_{g}$ is the moment of inertia of section and $A_{w}$ is the area of section.

Hysteretic model: The hysteretic model incorporates stiffness degradation $(\alpha)$, strength deterioration $(\beta)$, pinching behavior $(\gamma)$. The hysteretic model for flexural response is based on Takeda model as shown in Fig. 2 (Kunnath et al., 1990). 


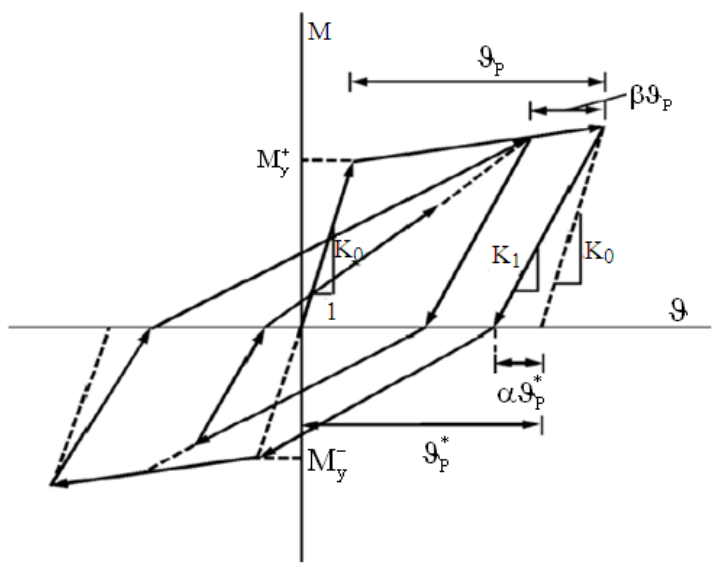

Fig. 2: Hysteretic model assumed in the nonlinear time history analysis

Failure criteria: Global failure was assumed to coincide with story failure; a dual criterion based on a limiting local drift of $2 \%$ and the simultaneous development of a sidesway collapse mechanism involving all vertical members was adopted for assessing story failure; regardless of mechanism formation, a structure was assumed to have collapse if the local drift at any location exceed a limit value of 3\% (Elnashai and Mwafy, 2001). In this study the failure criteria was assumed to have collapsed if the local drift exceed of 3, 2.5, 2 and $1 \%$ for SDF, IDF, ODF and GLD, respectively.

Description of $\mathrm{R} / \mathrm{C}$ moment resisting frames and earthquake ground motions:

Description of structures: Figure 3 shows the geometry of nine-story apartment building used for investigation. The building is selected to represent midrise buildings located in Bangkok as a low seismic zone. The selected buildings are beam-column reinforced concrete frame without shear wall. The rectangular plan of building measures $14.40 \mathrm{~m}$. by $35.10 \mathrm{~m}$. The story height is $2.50 \mathrm{~m}$. with a total height of $22.50 \mathrm{~m}$. The structural system is essentially symmetrical.

The buildings were designed according to the newly proposed seismic specification of Thailand; DPT 1302-52 and detailing by the provisions of UBC 1997 and of DPT standard 1301-50. To examine the influence of the design ductility class on the seismic behavior of the buildings, all frames were designed with ductility to 8,5 and 3 in order to examine the influence of the design ductility classes as moment resisting frames with Special Ductile (SDF), Intermediate Ductile (IDF) and Ordinary Ductile (ODF), respectively.
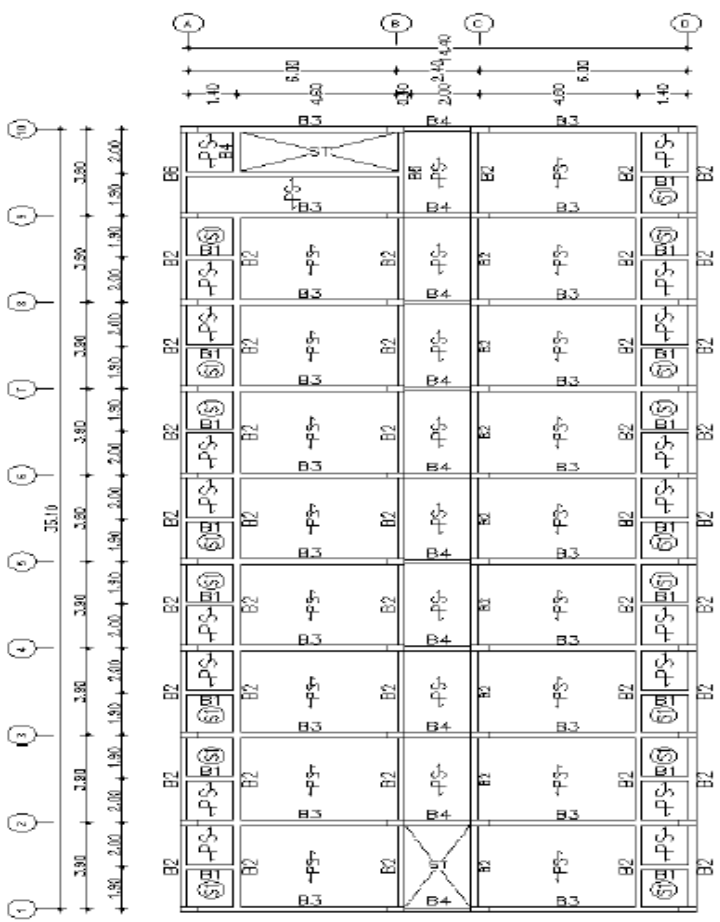

Fig. 3: Plan of nine-story reinforced concrete building

For the Gravity Load Designed frame (GLD), the structure was designed according to ACI (1995). Each pile is of I-shaped $0.30 \mathrm{~m}$ in size and $21 \mathrm{~m}$ in length. It is designed for a vertical safe load of 40 tons.

Material properties: The cylinder compressive strengths of concrete columns and beams are $240 \mathrm{ksc}$. The expected yield strengths of steel deformed and rounded bars are 3000 and $2400 \mathrm{ksc}$, respectively. The actual yield strength of steel reinforcement should be used in the evaluation of yield strength.

Factor load: The following factor loads are used for design. In case of gravity load, DL $=$ Structure self weight with load factor $(\alpha)$ set at $1.40, \mathrm{LL}=$ design live load with load factor $(\beta)$ set at 1.70 . These gravity load factors are introduced to the structure before applying lateral loads. When earthquake loads are applied, value of load factors is calculated by DL with load factor set at 1.20 , LL with load factor set at 0.50 and EQ = Design earthquake load with load factor $(\gamma)$ set at 1.00. In case of dead load combined with seismic load, value of load factors is calculated by DL with load factor set at 0.90 and EQ with load factor set at 1.00. For seismic evaluation, load factors of 1.0 and 0.30 for DL and LL, respectively, are applied to the structure and then the earthquakes loads are applied. 
Am. J. Engg. \& Applied Sci., 4 (1): 17-36, 2011

Table 1: Recorded ground motion details

\begin{tabular}{lllllll}
\hline EQ. & Year & Earthquake & Recording station & M & PGA $(\mathrm{g})$ & Epicenter distance $(\mathrm{km})$. \\
\hline ELC40 & 1940 & El centro & El centro irrigation district & 7.0 & 0.319 & 8.30 \\
SBK & $*$ & $\begin{array}{l}\text { Simulated ground motion at } \\
\text { Bangkok site }\end{array}$ & & & & \\
LP89stg & 1989 & Loma prieta aloha eve & Saratoga & 6.9 & 0.512 & 13.00 \\
LP89cfh & 1989 & Loma prieta & SF-cliffhouse & 6.9 & 0.075 & 84.40 \\
KC52sba & 1952 & Kern county & Santa barbara courthouse & 7.4 & 0.127 & 87.00 \\
\hline
\end{tabular}

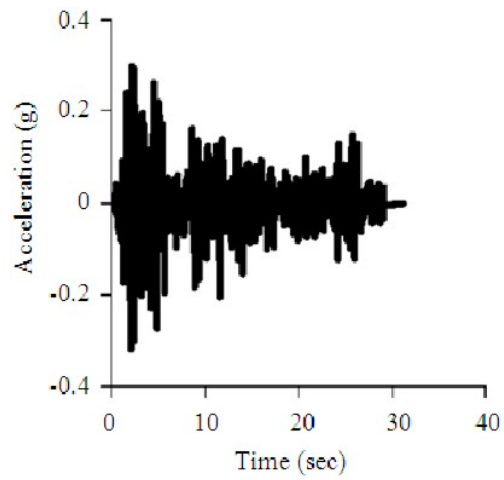

(a)

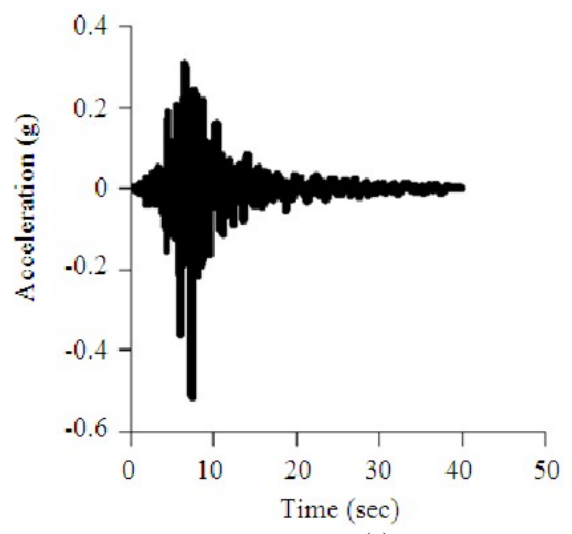

(c)

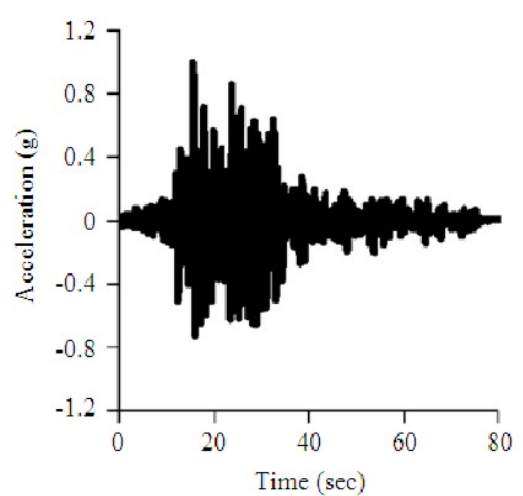

(b)

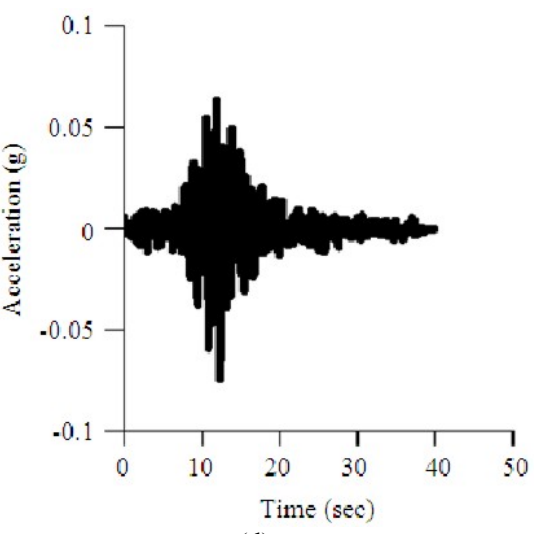

(d)

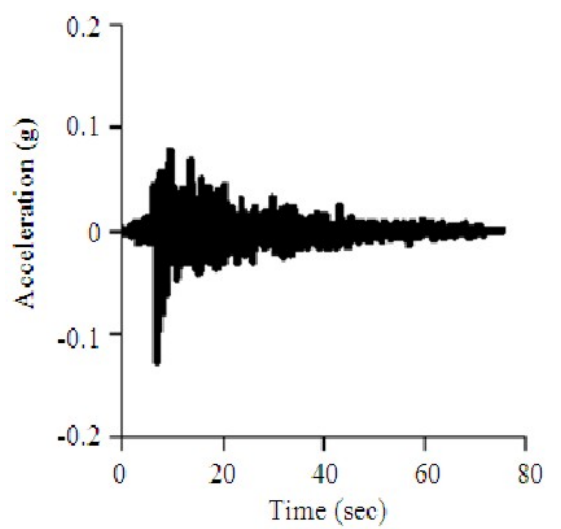

(e)

Fig. 4a: Ground motions a: ELC40 b: SBK c: LP89stg d: LP89cfh e. KC52sba 
Am. J. Engg. \& Applied Sci., 4 (1): 17-36, 2011

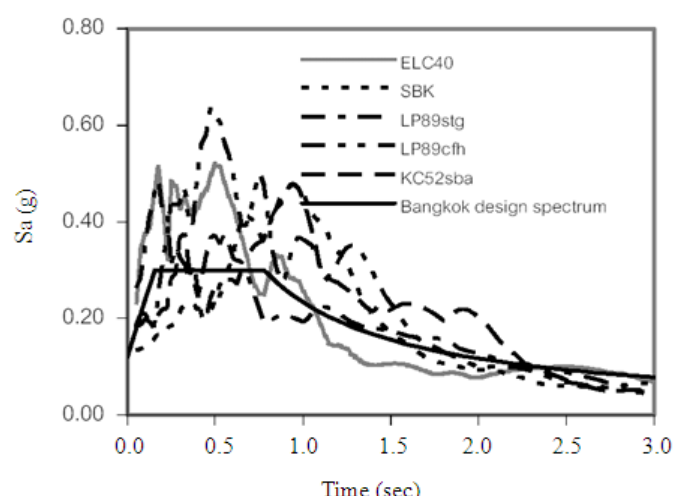

(b)

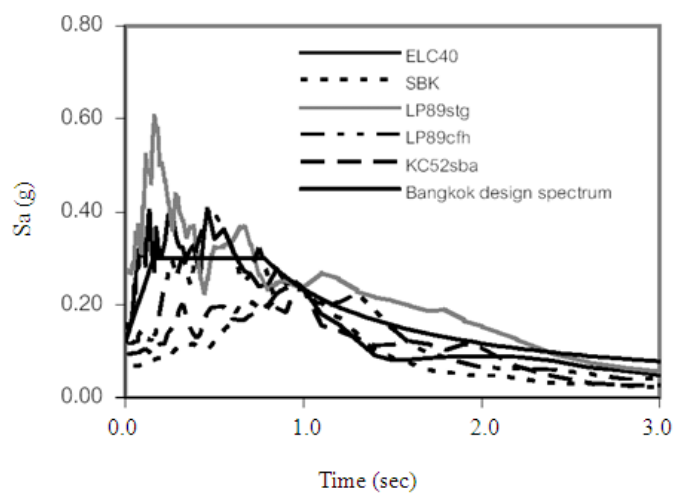

(c)

Fig. $4 \mathrm{~b}$ and c: Comparison of $5 \%$ damped scaled spectra among selected ground motions scaled to a design earthquake and Bangkok elastic design spectrum by scaling (b) and by spectra scaling (c)

Earthquake ground motions: A set of five ground motions in Table 1 was selected for nonlinear time history analysis. They were selected from the database for Pacific Earthquake Engineering Research Center (PEER). Details of these records are given in Table 1 and their 5\% damped elastic acceleration response spectra are shown in Fig. 4. To illustrate the difference of scaling technique, two methods are investigated in this study. The selected ground motions are scaled by two methods according to the newly proposed seismic specification of Thailand. Method A (PGA scaling), selected ground motions were scaled to the intensity of the 5\% damped Bangkok design spectrum of a PGA $=0.18 \mathrm{~g}$. Method B (spectra scaling), selected ground motions were scaled such that the spectral acceleration at the fundamental period matches a $5 \%$ damped Bangkok design spectrum of a PGA $=0.18 \mathrm{~g}$.

\section{Evaluation of the design methodology:}

Analysis and design of frames: Buildings evaluated were designed according to the newly proposed seismic specifications of Thailand and were located in Bangkok, a low seismic zone and assumed to be built on very soft soil (soil site class E). They were designed for an earthquake with a $2 \%$ probability of exceedance in 50 years. $\mathrm{S}_{\mathrm{S}}$ is the spectral response acceleration parameters at short period at $0.20 \mathrm{sec}$ equal to $0.18, \mathrm{~S}_{1}$ is the spectral response acceleration parameters at long period at $1.0 \mathrm{sec}$ equal to $0.10, \mathrm{~F}_{\mathrm{a}}$ is the site coefficient at short period at $0.20 \mathrm{sec}$ equal to $2.50, \mathrm{~F}_{\mathrm{v}}$ is the site coefficient at long period at $1.0 \mathrm{sec}$ equal to 3.50 . Soil type classification is very soft soil (E). I is the seismic occupancy importance factor assumed to be 1.0 as the building for typical apartment. According to this specification, the intensity of the design spectrum for a

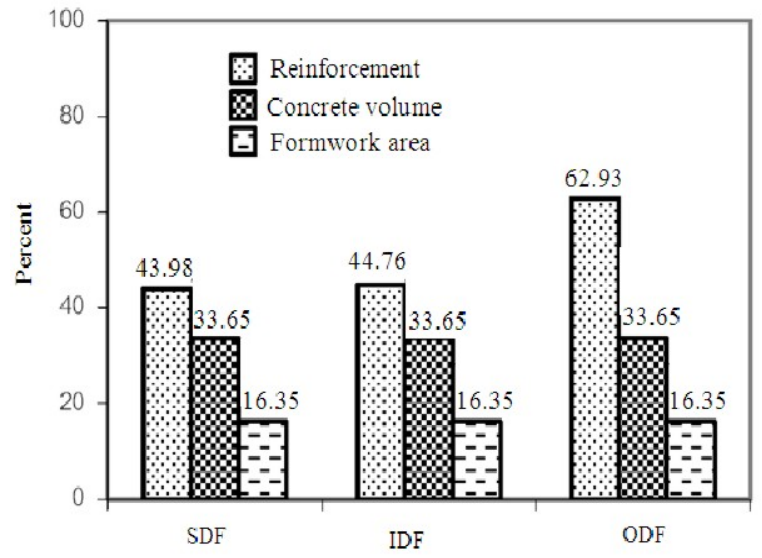

Fig. 5: Increasing quantities of steel reinforcement, concrete and formwork area compared with GLD

PGA of $0.18 \mathrm{~g}$ was assumed. On response modification factor, frames were designed with ductility from 8,5 and 3 in order to examine the influence of the design ductility classes as moment resisting frames with Special Ductile (SDF), Intermediate Ductile (IDF) and Ordinary Ductile (ODF) frames, respectively.

Four study cases totally of capacity and gravity load designed buildings are compared and evaluated using finite element program SAP2000. These sections are carried out in order to investigate the class of ductility.

Effect of ductility class on cost: For frame buildings on very soft soil, SDF, IDF and ODF are required the same of concrete volume and formwork area. The required concrete volumes and formwork area of all frames are increased 33.65 and $16.35 \%$ compared to GLD as shown in Fig. 5. For reinforcement, SDF 
Am. J. Engg. \& Applied Sci., 4 (1): 17-36, 2011

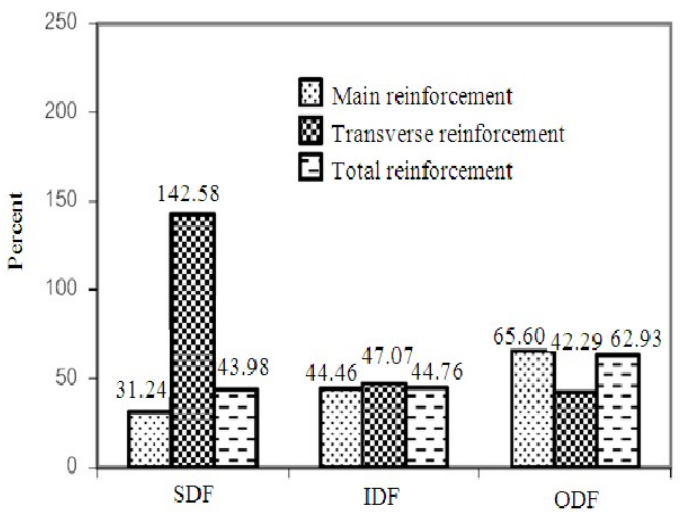

Fig. 6: Increasing quantities of steel reinforcement compared with GLD

required less main reinforcement but more transverse reinforcement than IDF and ODF as shown in Fig. 6. Compared to GLD, the results show that the required main reinforcement of SDF, IDF and ODF are increased $31.24,44.46$ and $65.60 \%$, respectively, transverse reinforcement are increased 142.58, 47.07 and $42.29 \%$, respectively and the total reinforcement are increased $43.98,44.76$ and $62.93 \%$ respectively. These are a significant effect of the ductility class. With increasing ductility class, the percentage of main reinforcement decreases, while that of transverse reinforcement increased. It was found that ODF is the most expensive and the costs of special and intermediate ductile frames are quite similar according to the newly proposed seismic specification of Thailand and detailing by the provisions of UBC 1997 and of DPT standard 1301-50.

Analysis and design of Intermediate Ductile Frames (IDF): The dimensions of all columns and beams in the direction of loading are as shown in Table 2. The dead load and base shear of the building are calculated as 464 Ton and 27.84 Ton. Sizes of columns and beams were determined based on the application of capacity design at the joints, according to UBC1997, which imposes the requirement that $\sum \mathrm{M}_{\mathrm{e}} \geq \sum \mathrm{M}_{\mathrm{g}}$ where $\sum M_{e}$ is sum of moments at the center of the joint corresponding to the design flexural strength of the columns and $\sum \mathrm{M}_{\mathrm{g}}$ is sum of moments at the center of the joint corresponding to the design flexural strength of the beams. In addition, all components of intermediate ductile frame must satisfy the applicable intermediate proportioning and detailing requirement to have a level of toughness adequate.

It was determined that the modal mass percentage in the first three modes is $77.10,9.10$ and 4.30,
Table 2: Cross sections summaries of designed for immediate ductile columns and beams

\begin{tabular}{|c|c|c|c|c|}
\hline Story & Description & $\begin{array}{l}\text { Dimensions } \\
\text { (m) }\end{array}$ & Reinforcement & Stirrup \\
\hline $1-2$ & $\mathrm{C} 1$ & $0.40 \times 0.40$ & 12-DB25 & $\begin{array}{l}\text { 3-RB9@0.15(10) } \\
\text { 3-RB9@0.20(11) }\end{array}$ \\
\hline $3-5$ & $\mathrm{C} 2$ & $0.40 \times 0.40$ & 12-DB25 & $\begin{array}{l}\text { 3-RB9@0.15(10) } \\
\text { 3-RB9@0.20(11) }\end{array}$ \\
\hline $6-9$ & $\mathrm{C} 3$ & $0.40 \times 0.40$ & 12-DB25 & $\begin{array}{l}3-R B 9 @ 0.15(10) \\
3-R B 9 @ 0.20(11)\end{array}$ \\
\hline $1-9$ & B3 & $0.25 \times 0.50$ & $\begin{array}{l}\text { 6-DB20 (T) } \\
\text { 6-DB20 (B) }\end{array}$ & $\begin{array}{l}\text { 1-RB9@0.125(10) } \\
1-R B 90.150\left(1_{1}\right)\end{array}$ \\
\hline $1-9$ & B4 & $0.25 \times 0.50$ & $\begin{array}{l}\text { 4-DB20 (T) } \\
4-\mathrm{DB} 20(\mathrm{~B})\end{array}$ & $\begin{array}{l}\text { 1-RB9@0.125(10) } \\
1-R B 90.150\left(1_{1}\right)\end{array}$ \\
\hline $1-9$ & B8 & $0.25 \times 0.50$ & $\begin{array}{l}\text { 3-DB20 (T) } \\
\text { 3-DB20 (B) }\end{array}$ & $\begin{array}{l}\text { 1-RB9@0.125(10) } \\
1-R B 90.150\left(1_{1}\right)\end{array}$ \\
\hline
\end{tabular}

Note: $1_{0}$ is a length from each joint face on both sides where flexural yielding may occur and $l_{1}$ is a total length of member-10. $l_{0}$ are $0.50 \mathrm{~m}$ and $1.00 \mathrm{~m}$ for column and beam, respectively. T, B are top and bottom reinforcements, respectively

Table 3: Elastic modal properties for IDF

\begin{tabular}{lrll}
\hline & Mode1 & Mode2 & Mode3 \\
\hline Modal periods, $\mathrm{T}_{\mathrm{n}}$ & 0.990 & 0.308 & 0.174 \\
Modal participant factors, $\Gamma_{\mathrm{n}}$ & 1.323 & 0.455 & 0.321 \\
Modal mass (\%) & 77.100 & 9.10 & 4.300 \\
\hline
\end{tabular}

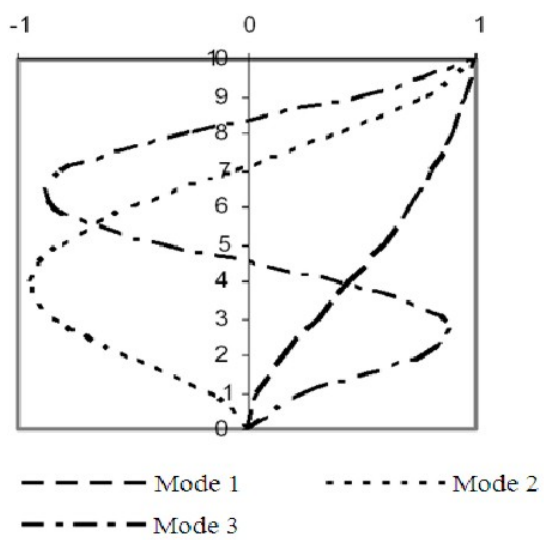

Fig. 7: Elastic modal shapes of the first three modes for IDF

respectively. The contribution of first three modes is about $90.50 \%$ of the modal contributions to the response as shown in Table 3 . The corresponding modal shapes are shown in Fig. 7. The resultant modal capacity curves in terms of normalized base shear with reactive weight versus roof drift ratio are presented in Fig. 8. Each capacity curve represents the capacity of building for each mode. Figure 9 shows the failure mechanisms and the symbol indicates flexural yielding and indicates local failure.

The IDF is designed for a base shear of $6 \% \mathrm{~W}$. The maximum lateral loads that the structure can resist for first three modes are 15.41, 20.67 and $23.50 \% \mathrm{~W}$, 
Am. J. Engg. \& Applied Sci., 4 (1): 17-36, 2011

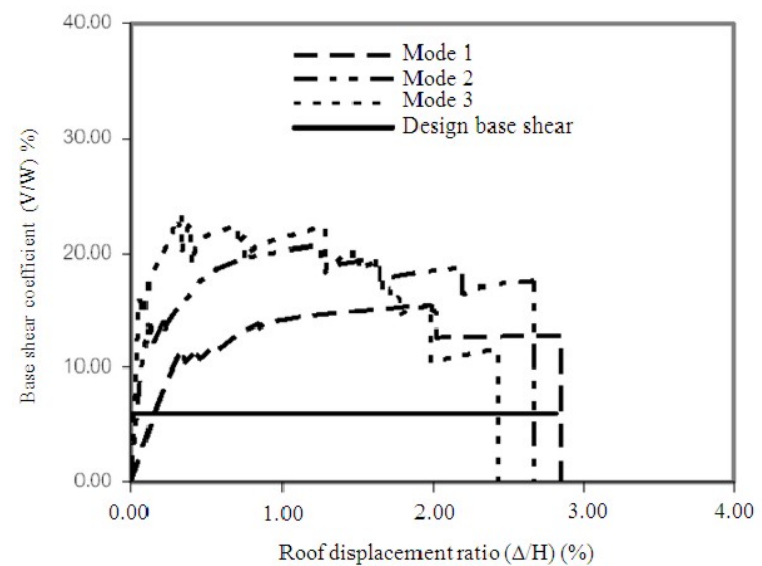

Fig. 8: Capacity curve based on separate pushover analysis for IDF

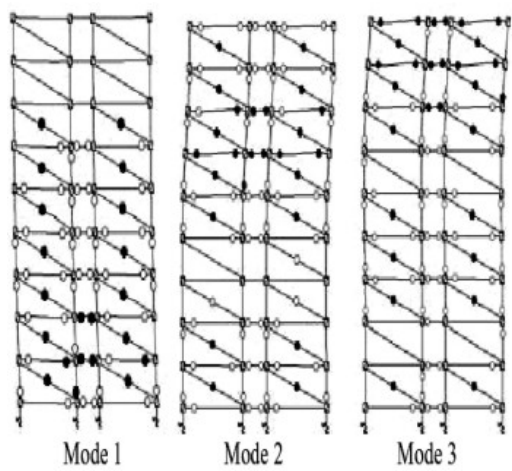

Fig. 9: Failure mechanisms on separate pushover analysis for IDF

respectively, where $\mathrm{W}$ is total weight of the building and under this load the maximum roof displacements for first three modes are 1.98, 1.26 and $1.28 \% \mathrm{H}$, respectively, where $\mathrm{H}$ is total height of building. The overstrength factor at maximum base shear is equal to 2.57 for the first mode. The first yielding of a beam occurred at base shear coefficient (base shear divide by total weight) of $10.78,13.64$ and $11.12 \%$ for the first three modes. The first yielding of a column occurred at a base shear coefficient of 11.81, 15.04 and $18.04 \%$ for the first three modes.

Finally, to indicate differences between modal pushover and nonlinear time history analysis, IDF was analyzed and a suite of record ground motions scaled such that the spectral acceleration at the fundamental period matches a 5\% damped Bangkok design spectrum. The comparisons of modal pushover analysis with nonlinear time history analysis are shown in Fig. 10 and 11. Figure 10 shows floor displacement

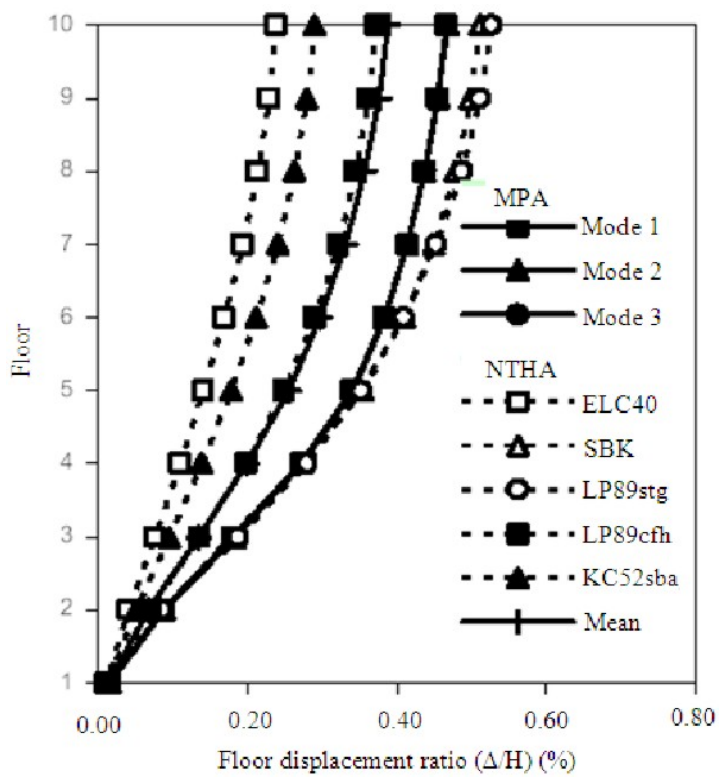

Fig. 10: Floor displacement ratios in each mode for IDF under a suite of ground motion records by MPA and NTHA with a design earthquake by spectra scaling

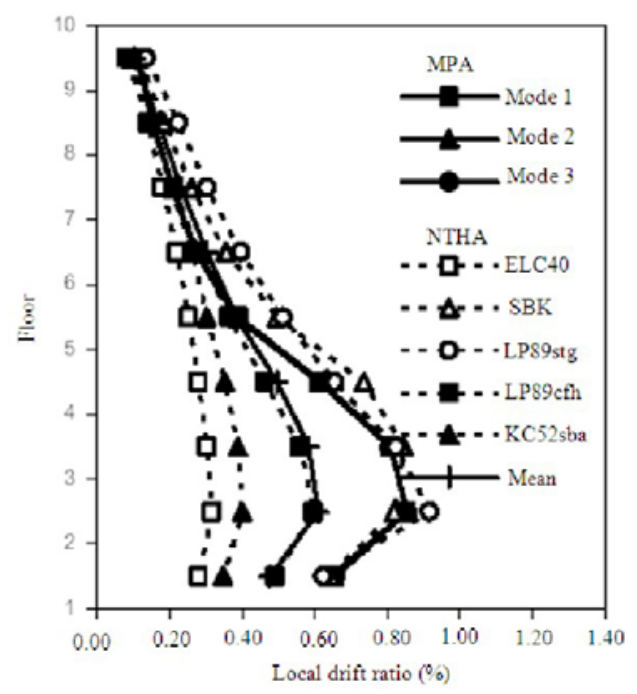

Fig. 11: Local drift ratios in each mode for IDF under a suite of ground motion records by MPA and NTHA with a design earthquake by spectra scaling

ratios, Fig. 11 shows story drift ratios and Fig. 12 shows plastic hinge mechanisms. It can be seen that the roof displacement and story drift ratios resulting from MPA are 0.47 and 0.85 , respectively. The average values of the roof displacement and story drift ratios resulting 


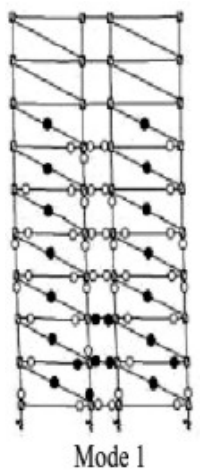

(a)

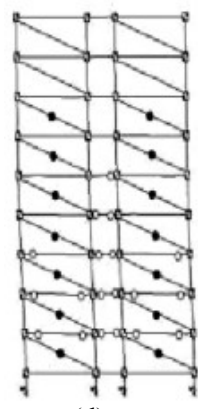

(d)

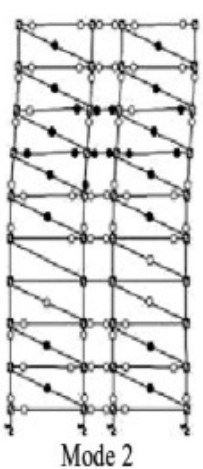

(b)

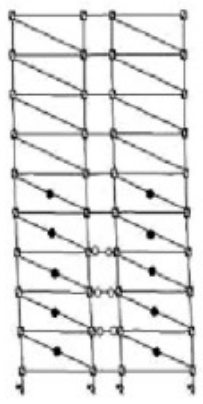

(e)

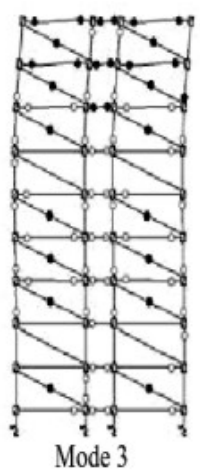

(c)

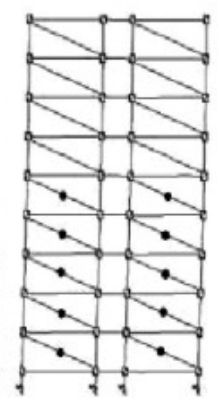

(f)
Fig. 12: Plastic hinge mechanisms for IDF under a suite of ground motions by MPA and NTHA with a design earthquake by spectra scaling (a) MPA: 3 modes (b) ELC40 (c) SBK (d) LP89stg (e) LP89cfh (f) KC52sba

from NTHA are 0.39 and 0.61 , respectively. The local drift ratio of the frame building does not exceedthe limits of $2 \%-3 \%$ of storey height.

In plastic hinge mechanism, it can be observed that infill wall cracks at 1st-6th floor, yielding of B3 beams at 2nd-4th floor and B4 beams at 2nd-5th floor occur when subjected to SBK. The analysis results reveal that seismic damages at 2 nd and 3 rd floor are higher than those of the other stories. When compared to NTHA, patterns of local drift and floor displacement ratios of MPA including three modes is quite similar but MPA including three modes overestimates the story drift of the lower floors and quite similar for the story drift of the upper floors. In addition, it can be seen that all results from NTHA are many effects by earthquake ground motion.

Effect on design earthquake intensity: For comparisons the responses subjected to level of intensity of design spectrum, IDF is investigated and a suite of record ground motions scaled such that the

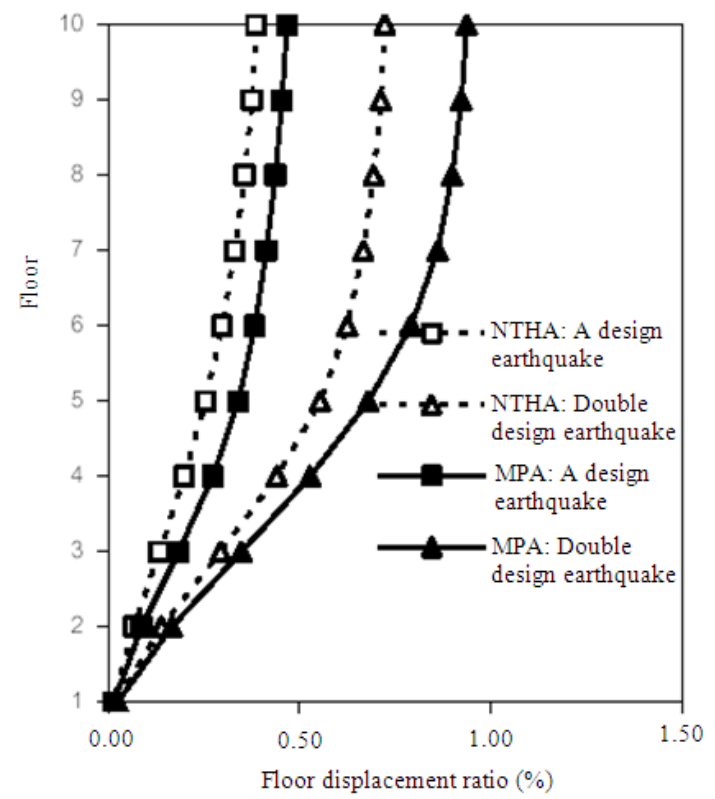

Fig. 13: Average floor displacement ratios of IDF under 5 ground motions by MPA and NTHA with a design and double design earthquakes by spectra scaling

spectral acceleration at the fundamental period matches a 5\% damped Bangkok design spectrum. Figure 13 and 14 summarized the average floor displacement and local drift ratios of IDF resulting from the suite of ground motion records used in inelastic analysis subjected to the a design and double design earthquakes. The story drift ratios resulting from MPA are 0.85 and $1.64 \%$ for a design and double design earthquakes, respectively. The average values of the story drift ratios resulting from MPA are 0.61 and $1.39 \%$ for a design and double design earthquakes, respectively. In plastic hinge mechanism with a design earthquake, with a design earthquake, it can be observed that infill wall cracks at 1st-6th floor, yielding of B3 beams at $2^{\text {nd }}-4^{\text {th }}$ floor and B4 beams at $2^{\text {nd }}-5^{\text {th }}$ floor occur when subjected to SBK. With double design earthquake, it can be observed that infill wall cracks at $1^{\text {st }}-6^{\text {th }}$ floor, yielding of B3 beams at $2^{\text {nd }}-5^{\text {th }}$ floor, B4 beams at $1^{\text {st }}-6^{\text {th }}$ floor and $\mathrm{C} 1$ columns at 1 st floor occur when subjected to SBK. As can be seen in Fig. 14, the seismic damages subjected to a design earthquake are less than those to double design earthquake. The analysis results reveal that seismic damages at $2 \mathrm{nd}$ and 3rd floor are higher than those of the other stories subjected to a design and double design earthquakes. It also indicates that the local drift ratios of the frame buildings do not exceed the failure limits of 2 and 3\% 
Am. J. Engg. \& Applied Sci., 4 (1): 17-36, 2011

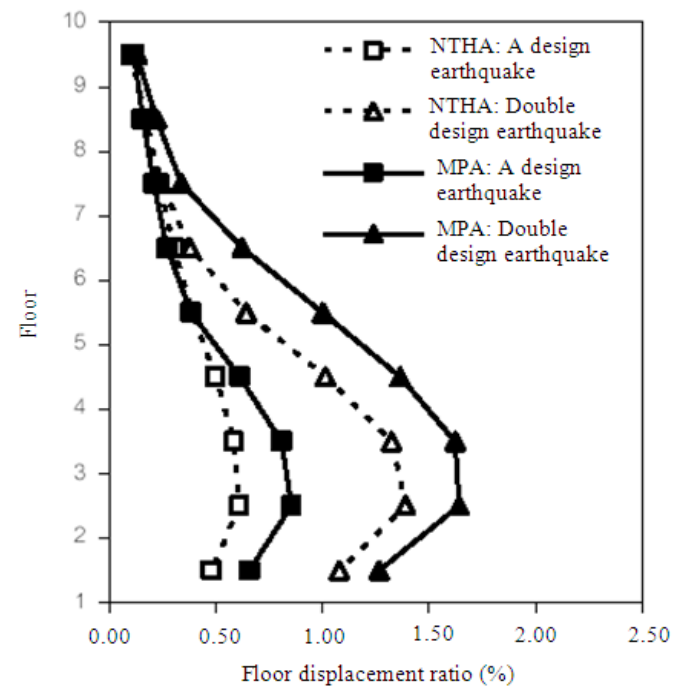

Fig. 14: Average local drift ratios of IDF under 5 ground motions by MPA and NTHA with a design and double design earthquakes by spectra scaling

of storey height. According to the study, deformations of structures are not critical under a design and double design earthquakes. However, they may cause the structures to collapse.

Analysis and design of Ordinary Ductile Frames (ODF): The dimensions of all columns and beams in the direction of loading are as shown in Table 4. The dead load and base shear of the building are calculated as 464 Ton and 46.4 Ton. It was determined that the modal mass percentage in the first three modes is 77.10 , 9.10 and 4.30 , respectively. The contribution of first three modes is about $90.50 \%$ of the modal contributions to the response.

The ODF is designed for a base shear of $10 \% \mathrm{~W}$. The maximum lateral loads that the structure can resist for first three modes are $22.45,19.17$ and $20.21 \% \mathrm{~W}$, respectively, where $\mathrm{W}$ is total weight of the building and under this load the maximum roof displacements for first three modes are 2.13, 0.86 and $0.56 \% \mathrm{H}$, respectively, where $\mathrm{H}$ is total height of building. The over strength factor at maximum base shear is equal to 2.25 for the first mode. The first yielding of a beam occurred at base shear coefficient of 12.71, 13.21 and $15.98 \%$ for the first three modes. The first yielding of a column occurred at a base shear coefficient of 16.28, 14.42 and $13.87 \%$ for the first three modes.

Finally, to indicate differences between modal pushover and nonlinear time history analysis, ODF was analyzed and a suite of record ground motions scaled such that the spectral acceleration at the fundamental
Table 4: Cross sections summaries of designed for ordinary ductile columns and beams

\begin{tabular}{lllll}
\hline \multicolumn{5}{c}{ columns and beams } \\
Story & Description & $\begin{array}{l}\text { Dimensions } \\
(\mathrm{m})\end{array}$ & Reinforcement & Stirrup \\
\hline $1-2$ & C1 & $0.40 \times 0.40$ & 16-DB25 & 3-RB9@0.20(10) \\
& & & & 3-RB9@0.20(11) \\
$3-5$ & C2 & $0.40 \times 0.40$ & 12-DB25 & 3-RB9@0.20(10) \\
& & & & 3-RB9@0.20(11) \\
$6-9$ & C3 & $0.40 \times 0.40$ & 12-DB20 & 3-RB9@0.20(10) \\
& & & & 3-RB9@0.20(11) \\
$1-9$ & B3 & $0.25 \times 0.50$ & 5-DB25 (T) & 1-RB9@0.150(10) \\
& & & 5-DB25 (B) & 1-RB9@0.150(11) \\
$1-9$ & B4 & $0.25 \times 0.50$ & 4-DB25 (T) & 1-RB9@0.150(10) \\
& & & 4-DB25 (B) & 1-RB9@0.150(11) \\
$1-9$ & B8 & $0.25 \times 0.50$ & 3-DB20 (T) & 1-RB9@0.150(10) \\
& & & 3-DB20 (B) & 1-RB9@0.150(11) \\
\hline
\end{tabular}

Note: $1_{0}$ is a length from each joint face on both sides where flexural yielding may occur and $l_{1}$ is a total length of member-10. $l_{0}$ are $0.50 \mathrm{~m}$ and $1.00 \mathrm{~m}$ for column and beam, respectively. T, B are top and bottom reinforcements, respectively

period matches a 5\% damped Bangkok design spectrum. It can be seen that the roof displacement and story drift ratios resulting from MPA are 0.49 and $0.76 \%$, respectively. The average values of the roof displacement and story drift ratios resulting from NTHA are 0.42 and $0.59 \%$, respectively. The local drift ratio of the frame building does not exceed the limits of $2-3 \%$ of storey height.

In plastic hinge mechanisms, it can be observed that infill wall cracks at 1st-7th floor and yielding of B4 beams at $2^{\text {nd }}-4^{\text {th }}$ floor occur when subjected to SBK. The analysis results reveal that seismic damages at $2^{\text {nd }}$ and $3^{\text {rd }}$ floor are higher than those of the other stories. When compared to NTHA, patterns of local drift and floor displacement ratios of MPA including three modes is quite similar but MPA including three modes overestimates the story drift of the lower floors and quite similar for the story drift of the upper floors.

Analysis and design of Special Ductile Frames (SDF): The dimensions of all columns and beams in the direction of loading are as shown in Table 5. The dead load and base shear of the building are calculated as 464 Ton and 17.4 Ton. It was determined that the modal mass percentage in the first three modes is 77.10 , 9.10 and 4.30 , respectively. The contribution of first three modes is about $90.50 \%$ of the modal contributions to the response.

The SDF is designed for a base shear of $3.75 \% \mathrm{~W}$. The maximum lateral loads that the structure can resist for first three modes are 13.27, 18.54 and $20.93 \% \mathrm{~W}$, respectively, where $\mathrm{W}$ is total weight of the building and under this load the maximum roof displacements for first three modes are $2.39,1.69$ and $0.39 \% \mathrm{H}$, respectively, where $\mathrm{H}$ is total height of building. The first yielding of a beam occurred at base shear coefficient of $6.93,10.59$ 
Am. J. Engg. \& Applied Sci., 4 (1): 17-36, 2011

Table 5: Cross sections summaries of designed for special ductile columns and beams

\begin{tabular}{lllll}
\hline \multicolumn{5}{c}{ Dimensions } \\
Story & Description & $(\mathrm{m})$ & Reinforcement & Stirrup \\
\hline $1-2$ & C1 & $0.40 \times 0.40$ & 12-DB25 & 3-RB9@0.10(10) \\
& & & & 3-RB9@0.20(11) \\
$3-5$ & C2 & $0.40 \times 0.40$ & 12-DB25 & 3-RB9@0.10(10) \\
& & & & 3-RB9@0.20(11) \\
$6-9$ & C3 & $0.40 \times 0.40$ & 12-DB25 & 3-RB9@0.10(10) \\
& & & & 3-RB9@0.20(11) \\
$1-9$ & B3 & $0.25 \times 0.50$ & 5-DB20 (T) & 1-RB9@0.100(10) \\
& & & 5-DB20 (B) & 1-RB9@0.150(11) \\
$1-9$ & B4 & $0.25 \times 0.50$ & 3-DB20 (T) & 1-RB9@0.100(10) \\
& & & 3-DB20 (B) & 1-RB9@0.150(11) \\
$1-9$ & B8 & $0.25 \times 0.50$ & 3-DB20 (T) & 1-RB9@0.100(10) \\
& & & 3-DB20 (B) & 1-RB9@0.150(11) \\
\hline
\end{tabular}

Note: $1_{0}$ is a length from each joint face on both sides where flexural yielding may occur and $l_{1}$ is a total length of member-10. 10 are $0.50 \mathrm{~m}$ and $1.00 \mathrm{~m}$ for column and beam, respectively. T, B are top and bottom reinforcements, respectively

and $10.69 \%$ for the first three modes. The over strength factor at maximum base shear is equal to 3.54 for the first mode. The first yielding of a column occurred at a base shear coefficient of $10.86,15.84$ and $14.59 \%$ for the first three modes.

Although the design lateral load for SDF was reduced to five-eighths of that of IDF, the sizes of columns and beams were determined based on the application of capacity design at the joints, according to UBC1997, which imposes the requirement that $\sum M_{e} \geq(6 / 5) \sum M_{g}$ where $\sum M_{g}$ is sum of moments at the center of the joint corresponding to the design flexural strength of the columns and $\sum \mathrm{M}_{\mathrm{g}}$ is sum of moments at the center of the joint corresponding to the design flexural strength of the beams. In addition, all components of special ductile frame must satisfy the applicable special proportioning and detailing requirement to have a level of toughness adequate.

Finally, to indicate differences between modal pushover and nonlinear time history analysis, SDF was analyzed and a suite of record ground motions scaled such that the spectral acceleration at the fundamental period matches a 5\% damped Bangkok design spectrum. It can be seen that the roof displacement and story drift ratios resulting from MPA are 0.45 and $0.84 \%$, respectively. The average values of the roof displacement and story drift ratios resulting from NTHA are 0.37 and $0.62 \%$, respectively. The local drift ratio of the frame building does not exceed the limits of $2 \%-3 \%$ of storey height.

In plastic hinge mechanism, it can be observed that infill wall cracks at 1st-6th floor, yielding of B3 beams at 2nd-4th floor and B4 beams at 1st-6th floor occur when subjected to SBK. The analysis results reveal that seismic damage between 3rd and 4th floor is higher
Table 6: Cross sections summaries of designed for gravity load designed columns and beams

\begin{tabular}{lllll}
\hline \multicolumn{5}{c}{ Dimensions } \\
Story & Description & $(\mathrm{m})$ & Reinforcement & Stirrup \\
\hline $1-2$ & C1 & $0.30 \times 0.40$ & 10-DB25 & 2-RB6@0.20 \\
$3-5$ & C2 & $0.30 \times 0.40$ & 8-DB25 & 2-RB6@0.20 \\
$6-9$ & C3 & $0.25 \times 0.40$ & 8-DB20 & 2-RB6@0.20 \\
$1-9$ & B3 & $0.25 \times 0.45$ & 5-DB20 (T) & 1-RB6@0.15 \\
& & & 5-DB20 (B) \\
$1-9$ & B4 & $0.25 \times 0.40$ & 3-DB25 (T) & 1-RB6@0.15 \\
& & & & 3-DB16(B) \\
$1-9$ & B8 & $0.25 \times 0.40$ & 4-DB16 (T) & 1-RB6@0.15 \\
& & & & 4-DB16 (B) \\
\hline
\end{tabular}

Note: T, B are top and bottom reinforcements, respectively

than those of the other stories. When compared to NTHA, patterns of local drift and floor displacement ratios of MPA including three modes is quite similar but MPA including three modes overestimates the story drift of the lower floors and quite similar for the story drift of the upper floors.

Analysis and design of Gravity Load Designed frame (GLD): The dimensions of all columns and beams in the direction of loading are as shown in Table 6. It was determined that the modal mass percentage in the first three modes is $75.60,10.56$ and 4.71 , respectively. The contribution of first three modes is about $90.87 \%$ of the modal contributions to the response.

The maximum lateral loads that the structure can resist for first three modes are 11.67, 11.14 and $11.26 \% \mathrm{~W}$, respectively, where $\mathrm{W}$ is total weight of the building and under this load the maximum roof displacements for first three modes are 1.09, 0.46 and $0.25 \% \mathrm{H}$, respectively, where $\mathrm{H}$ is total height of building. The first yielding of a beam occurred at base shear coefficient of 5.88, 6.40 and $5.65 \%$ for the first three modes. The first yielding of a column occurred at a base shear coefficient of $8.91,8.88$ and $8.00 \%$ for the first three modes. Finally, to indicate differences between modal pushover and nonlinear time history analysis, GLD was analyzed and a suite of record motion scaled such that the spectral acceleration at the fundamental period matches a 5\% damped Bangkok design spectrum. It can be seen that the roof displacement and story drift ratios resulting from MPA are 0.49 and $0.98 \%$, respectively. The average values of the roof displacement and story drift ratios resulting from NTHA are 0.48 and $0.88 \%$, respectively. The local drift ratio of the frame building does not exceed the limits of $2-3 \%$ of storey height.

In plastic hinge mechanism, it can be observed that infill wall cracks at 1st-5th floor, yielding of B3 beams at 2nd-4th, B4 beams at 1st-6th floor, $\mathrm{C} 1$ columns at $1^{\text {st }}$ floor and $\mathrm{C} 2$ columns at 2 nd- $3^{\text {rd }}$ occur when subjected 


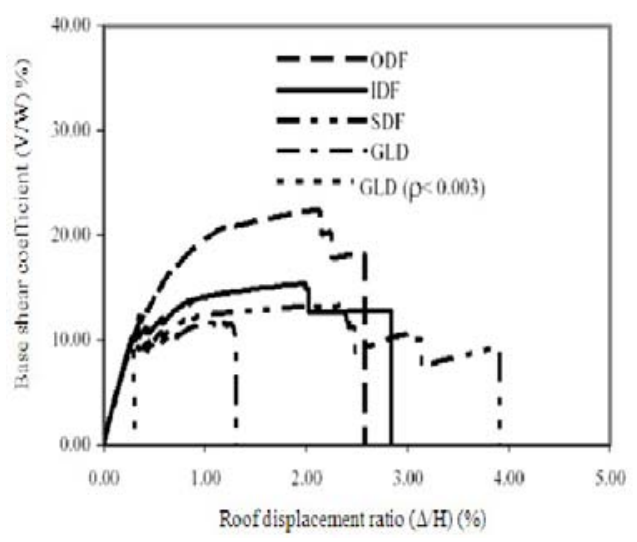

Fig. 15: Comparison of the modal pushover analyses (1st mode) for various frames

to SBK. The analysis results reveal that seismic damages at $2 \mathrm{nd}$ and $3 \mathrm{rd}$ floor are higher than those of the other stories. When compared to NTHA, patterns of local drift and floor displacement ratios of MPA including three modes is quite similar but MPA including three modes overestimates the story drift of the lower floors and quite similar for the story drift of the upper floors.

Comparisons of frames of all ductility classes: Four moment resisting frames are considered here designed according to the newly proposed seismic specification of Thailand. Modal pushover analysis is performed to construct capacity curve for the frames. The base shear and roof displacement for the first mode, capacity curve, for these structures are compared in Fig. 15. The maximum lateral loads that the structure can resist for Special (SDF), Intermediate (IDF) and Ordinary (ODF) ductile frames are $13.27,15.41$ and $22.45 \% \mathrm{~W}$, respectively, where $\mathrm{W}$ is total weight of the building and under this load the maximum roof displacements for first three modes are 2.39, 1.98 and $2.13 \% \mathrm{H}$, respectively, where $\mathrm{H}$ is total height of building. For Gravity Load Designed frame (GLD) that designed without considering earthquake force, it can resist the maximum base shear of $11.67 \% \mathrm{~W}$ at maximum roof displacement of $1.31 \% \mathrm{H}$. In addition, gravity load designed frame with volumetric ratio of horizontal confinement within joint panel $(\rho)$ less than 0.003 can resist the maximum base shear of $9.89 \% \mathrm{~W}$ at maximum roof displacement of $0.30 \% \mathrm{H}$. The seismic damage occurs at outer joint at 3rd floor.

The over strength factors on the first mode at maximum base shear are 3.54, 2.57 and 2.25 for SDF, IDF and ODF, respectively. For SDF, IDF and ODF the
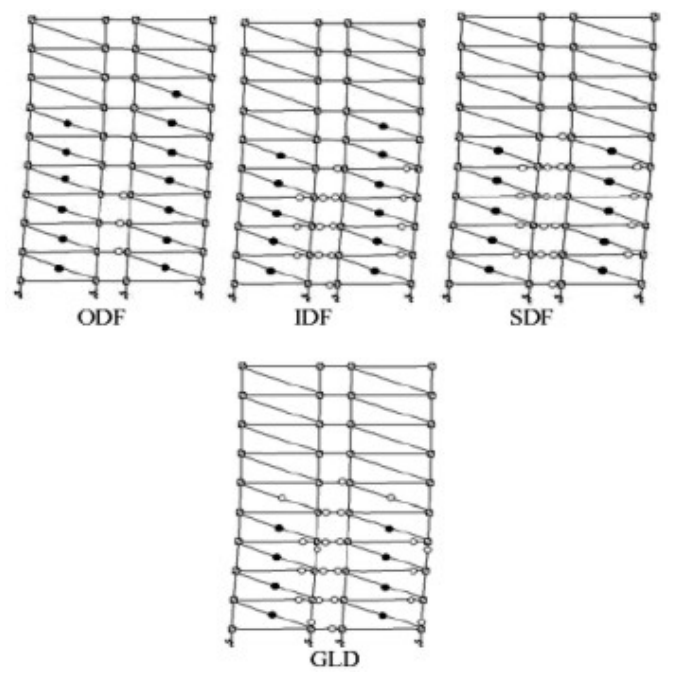

Fig. 16: Plastic hinge mechanisms for various frames under SBK w by MPA include 3 modes with a design earthquake by spectra scaling

over strength factors at the first yielding of a beam are $1.85,1.80$ and 1.27, respectively, while the over strength factors at the first yielding of a column are $2.90,1.97$ and 1.27 , respectively.

It can be seen that the yielding of beam happened before the yielding of column. It can be noted that the strength of SDF is slightly less than that of IDF although SDF was designed for five-eighths of the value of design lateral load of IDF. This is because all components of SDF must satisfy the applicable special proportioning and detailing requirement to have a level of toughness adequate. It indicated the successful application of the strong column weak beam implemented in the capacity design.

After performing pushover analysis, Nonlinear Time History Analysis (NTHA) has been performed because it is a power fool for the study of structural seismic response. The frames have been subjected to five earthquake ground motions. The plastic mechanisms are presented only for the various frames subjected to SBK as an example in Fig. 16 and 17. When all records were scaled such that the value of 5\% damped spectral acceleration at the fundamental period matches a design spectrum. Resulting from MPA for ODF, IDF, SDF and GLD, roof displacement ratios are $0.49,0.470 .45$ and $0.50 \%$, respectively and story drift ratios are $0.76,0.85,0.84$ and $0.98 \%$, respectively. Resulting from NTHA for ODF, IDF, SDF and GLD, roof displacement ratios are $0.63,0.51,0.48$ and $0.63 \%$, respectively and story drift ratios are $0.89,0.84,0.89$ and $1.12 \%$, respectively. 

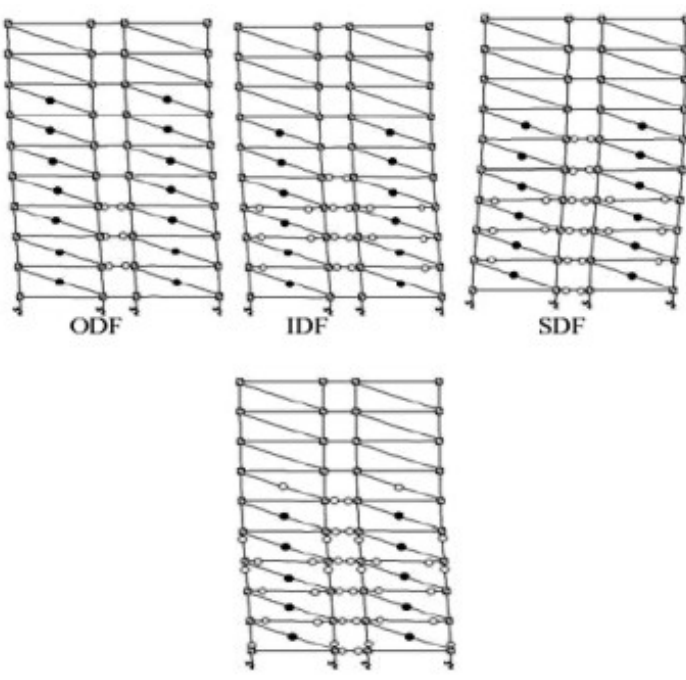

GLD

Fig. 17: Plastic hinge mechanisms for various frames under SBK by NTHA with a design earthquake by spectra scaling

It shows that the roof displacement ratio of SDF with modification factor of 8 is more ductile than ODF with modification factor of 3 . However, the strength of SDF is less than that of the ODF. For inelastic design, the SDF with modification factor of 8 decrease stiffness and increase deflection of structures.

Comparisons of scaling methods on record ground motions: For scaling method comparisons, all records of ground motions are scaled by two methods. Method A, all records of ground motions are scaled to the intensity of Bangkok design spectrum of the newly proposed seismic specification of Thailand for a PGA $=0.18 \mathrm{~g}$. It can be observed from the demand spectrum that the spectrum accelerations of each record of ground motions are different at the first mode. For method B, all records of ground motion shall be scaled such that the value of $5 \%$ damped spectral acceleration at the fundamental period matches a design spectrum. The results show that each ground motion records exhibits its own particularities, corresponded to frequency content. For various frames, SBK caused more damage to the structure components than the others because the fundamental mode of SBK is the predominant response of the frame.

By method A, it can be seen that the story drift ratios resulting from MPA are $0.98,1.05,1.10$ and $1.27 \%$ for ODF, IDF, SDF and GLD, respectively. The average values of the story drift ratios resulting from NTHA are $0.76,0.85,0.86$ and $1.08 \%$ for ODF, IDF, SDF and GLD, respectively. By method B, it can be

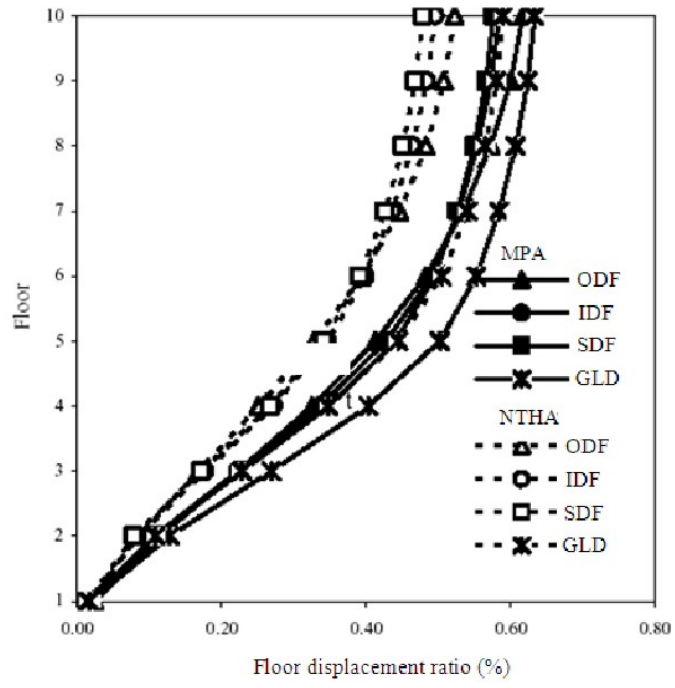

Fig. 18: Average floor displacement ratios under 5 ground motions by MPA and NTHA with a design earthquake by PGA scaling for various frames

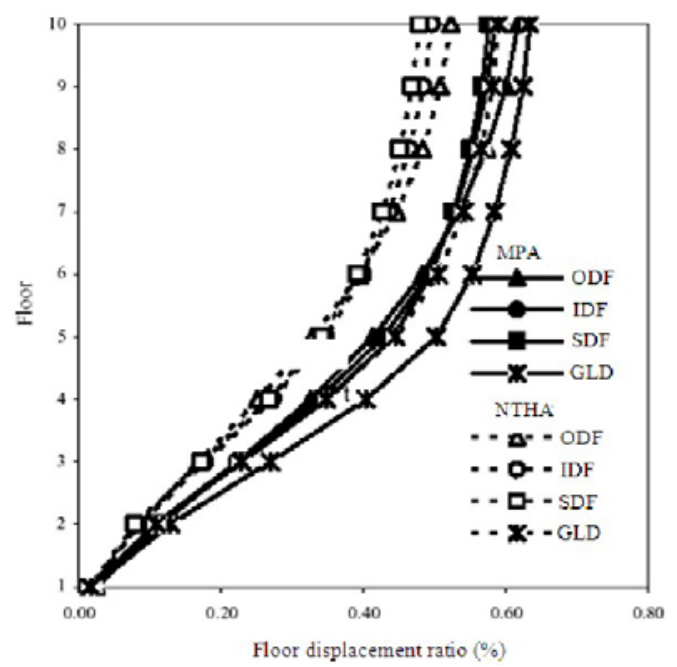

Fig. 19: Average local drift ratios under 5 ground motions by MPA and NTHA with a design earthquake by PGA scaling for various frames

seen that the story drift ratios resulting from MPA are $0.76,0.85,0.84$ and $0.98 \%$ for ODF, IDF, SDF and GLD, respectively. The average values of the story drift ratios resulting from NTHA are $0.59,0.61,0.62$ and $0.88 \%$ for ODF, IDF, SDF and GLD, respectively.

It was found that when all records of ground motions were scaled by method A and method B, roof displacement and local drift ratios by modal pushover and nonlinear dynamic procedures are slightly different as shown in Fig.18-21. However, patterns of local drift 
Am. J. Engg. \& Applied Sci., 4 (1): 17-36, 2011

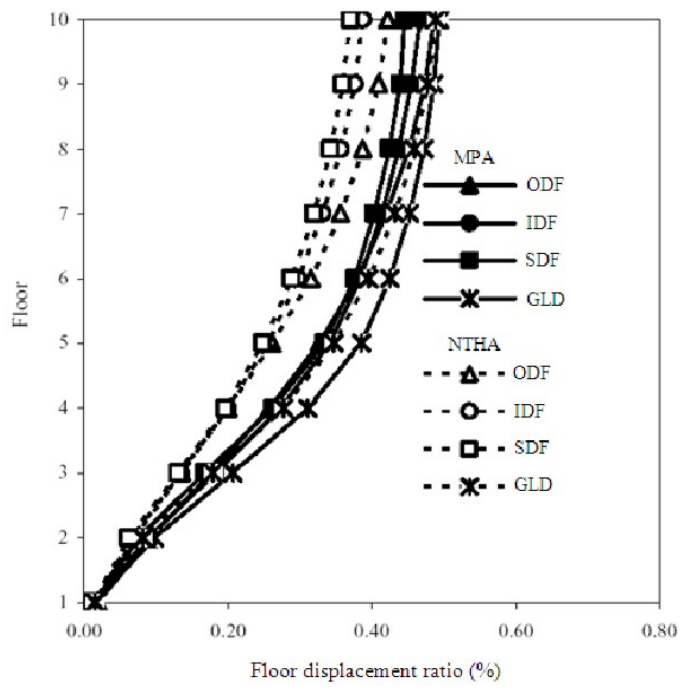

Fig. 20: Average floor displacement ratios under 5 ground motions by MPA and NTHA with a design earthquake by spectra scaling for various frames

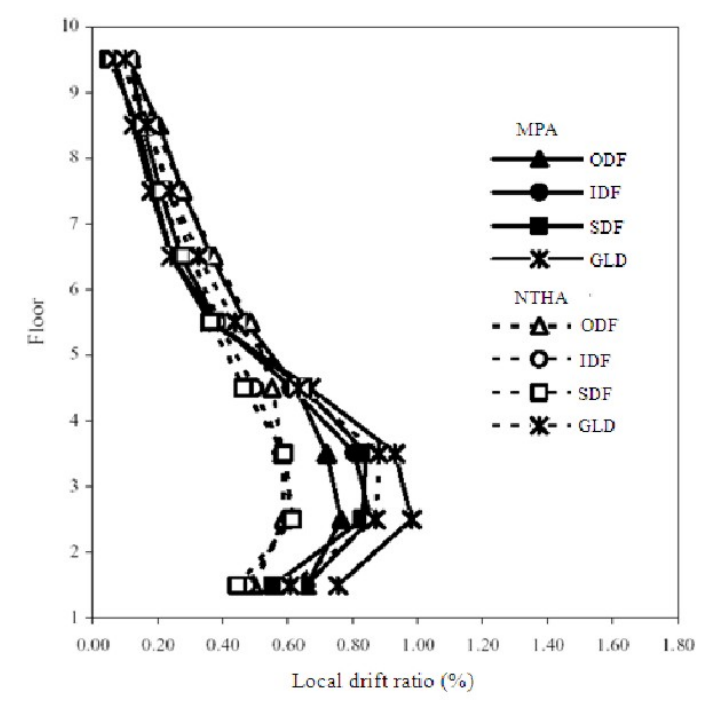

Fig. 21: Average local drift ratios under 5 ground motions by MPA and NTHA with a design earthquake by spectra scaling for various frames

and floor displacement ratios by the two methods are quite similar. It is important to note that local drift ratios from modal pushover analysis are overestimated at lower floors and quite equal at upper floors for frames of all ductility classes compared to responses using nonlinear time history analysis. The reason for this is that the nonlinear time history analysis assumed a hysteretic moment rotation relationship so the model can absorb energy through hysteretic damping. The local drift ratios of frames of all ductility classes do not exceed the limits of $2-3 \%$ of story height and seismic damages at 2nd and 3rd floor are higher than those of the other stories for frames of all ductility classes. In conclusion, frames of all ductility classes are to perform satisfactorily during design earthquake according to the newly proposed seismic specification of Thailand (DPT 1302-52) and detailing by the provisions of UBC 1997 and of DPT standard1301-50.

Performance point evaluations of frames of all ductility classes: In performance point evaluation the Equivalent Single Degree Of Freedom (ESDOF) is estimated by considering dynamic parameters such as modal participant factor and effective mass for the first mode. The seismic demand for the ESDOF system can be determined by using a graphical procedure. Both the demand spectrum and the capacity spectrum have been plotted in the same graph. Multi-story buildings are transformed in to ESDOF systems based on the outputs of the pushover analysis. The capacity curve in term of base shear and lateral roof displacement of the multistory building from pushover analysis is converted into the capacity curve of ESDOF systems.

Any points $\left(\mathrm{V}=\right.$ Base shear and $\Delta_{\text {roof }}=$ Lateral roof displacement) on the capacity curve for the fundamental mode are converted to the corresponding point $\mathrm{S}_{\mathrm{a}}$ (spectral acceleration) and $\mathrm{S}_{\mathrm{d}}$ (spectral displacement) on the capacity spectrum. The intersection of the capacity spectrum and the demand spectrum provides an estimate of the inelastic acceleration and displacement demand. This point represents the expected level of seismic demand on the structure. In this study, the performance point based on CSM in ATC (1996), procedure B, IDDM by Chopra and Goel (2002) and IDDM by Fajfar (2000) are compared under a suite of ground motion records with a design earthquake by PGA scaling. The detailed results of the evaluation are presented only for the IDF subjected to Kern County ground motion (KC52sba) recorded at Santa Barbara Courthouse station with a design earthquake. As an example, Fig. 22 shows the comparison of capacity and demand spectrum for various frames under KC52sba with a design earthquake.

Capacity Spectrum Method (CSM) in ATC-40: In this study the capacity spectrum method is the method used in procedure B of ATC (1996). The demand spectrums for damping ratios ranging from $5-20 \%$ and the $5 \%$ damping corresponds to the inherent damping. As an example, Fig. 23 presents the performance point 
Am. J. Engg. \& Applied Sci., 4 (1): 17-36, 2011

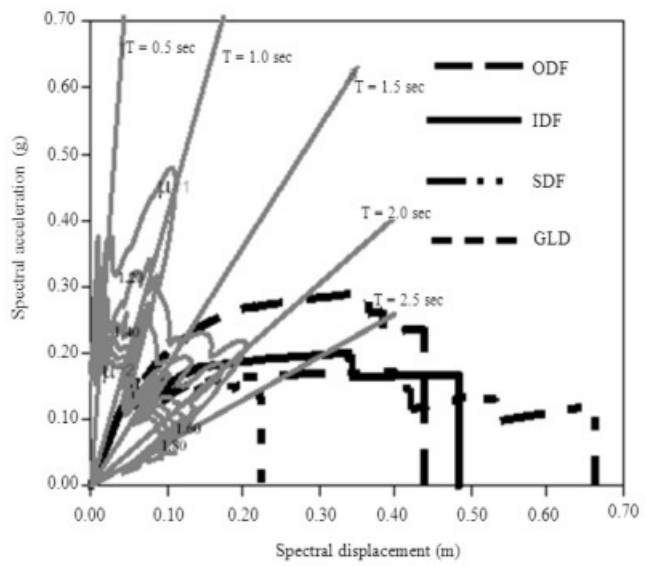

Fig. 22: Comparison of capacity and demand spectrum for various frames under KC52sba with a design earthquake

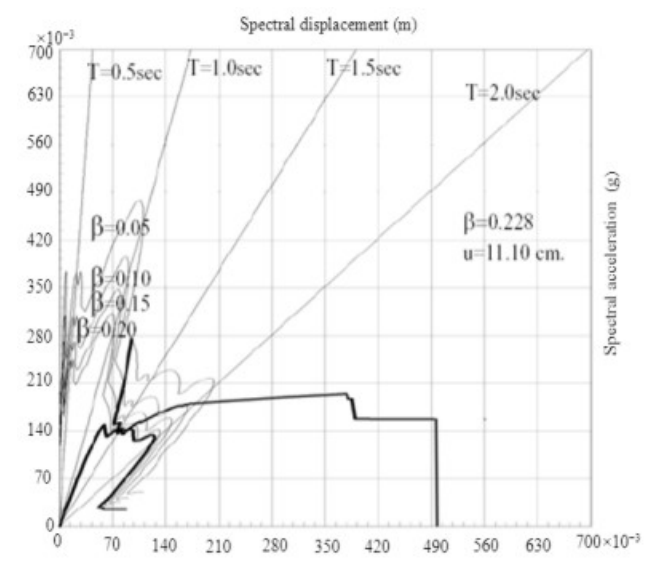

Fig. 23: Comparison of capacity and demand spectrum for IDF under KC52sba with a design earthquake By CSM in ATC-40

evaluation of IDF subjected to KC52sba with a design earthquake. At the performance point under a suite of ground motions with a design earthquake, the average ductilities for ODF, IDF, SDF and GLD are 1.11, 1.21, 1.26 and 1.23 , respectively.

The displacement demands at the performance point evaluations are given in Table 7. It is observed from the Table 7 that all frames performance with a design earthquake is predicted to be the immediate occupancy performance level.

Inelastic Demand Diagram Method (IDDM): Many researchers proposed constant-ductility design methods to evaluate the performance point of the buildings such as Fajfar (2000) and Chopra and Goel (2002). The inelastic response spectrums for ESDOF were
Table 7: Comparison of displacement demand for various frames resulting from CSM under a suite of ground motion records with a design earthquake

\begin{tabular}{lllllllll}
\hline & \multicolumn{7}{c}{ Displacement demand (cm.) } \\
& ODF & & IDF & & SDF & GLD & \\
EQ. & CSM & NTHA & CSM & NTHA & CSM & NTHA & CSM & NTHA \\
\hline ELC40 & 6.4 & 6.2 & 6.3 & 6.2 & 6.1 & 6.1 & 6.1 & 6.1 \\
SBK & 9.8 & 16.9 & 8.6 & 15.3 & 7.8 & 13.9 & 8.3 & 15.6 \\
LP89stg & 7.3 & 7.9 & 7.2 & 7.9 & 6.9 & 7.8 & 6.9 & 7.8 \\
LP89cfh & 12.8 & 13.0 & 10.1 & 12.8 & 9.3 & 12.8 & 9.1 & 13.1 \\
KC52sba & 9.8 & 14.8 & 11.1 & 13.5 & 11.6 & 13.3 & 11.8 & 14.5 \\
Average & 9.2 & 6.20 & 8.7 & 11.2 & 8.3 & 10.8 & 8.4 & 11.8 \\
\hline
\end{tabular}

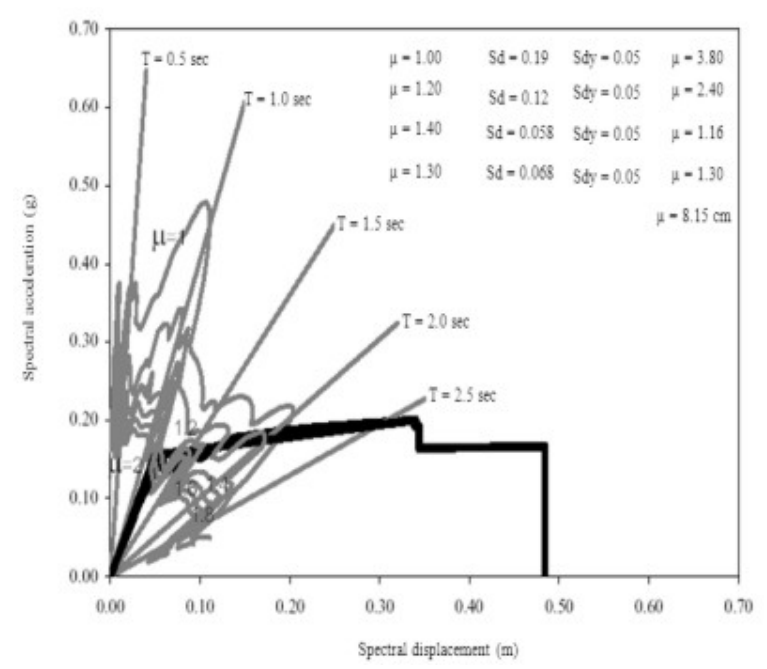

Fig. 24: Comparison of capacity and demand spectrum for IDF under KC52sba with a design earthquake by IDDM by Chopra and Goel (2002)

generated assuming elastoplastic systems. The demand spectrums for $5 \%$ damped ranging the ductility factor $(\mu)$ from 1-4 subjected to a suite of record ground motions used for the evaluation. The intersection between capacity and demand spectrum having the same ductility factor is the performance point. The system ductility demand is estimated by the ratio of yield displacement in capacity spectrum to inelastic maximum displacement in the performance point.

Chopra and Goel (2002) presented the performance procedure by graphical method with iteration. The static equivalent spectral displacement $\left(\mathrm{S}_{\mathrm{d}}\right)$ and spectral acceleration $\left(\mathrm{S}_{\mathrm{a}}\right)$ obtained from the pushover analysis. As an example, Fig. 24 presents the performance point evaluation of IDF subjected to KC52sba with a design earthquake. At the performance point under a suite of ground motions with a design earthquake, the average ductilities for ODF, IDF, SDF and GLD are 1.13, $1.30,1.33$ and 1.32 , respectively. The displacement 
Am. J. Engg. \& Applied Sci., 4 (1): 17-36, 2011

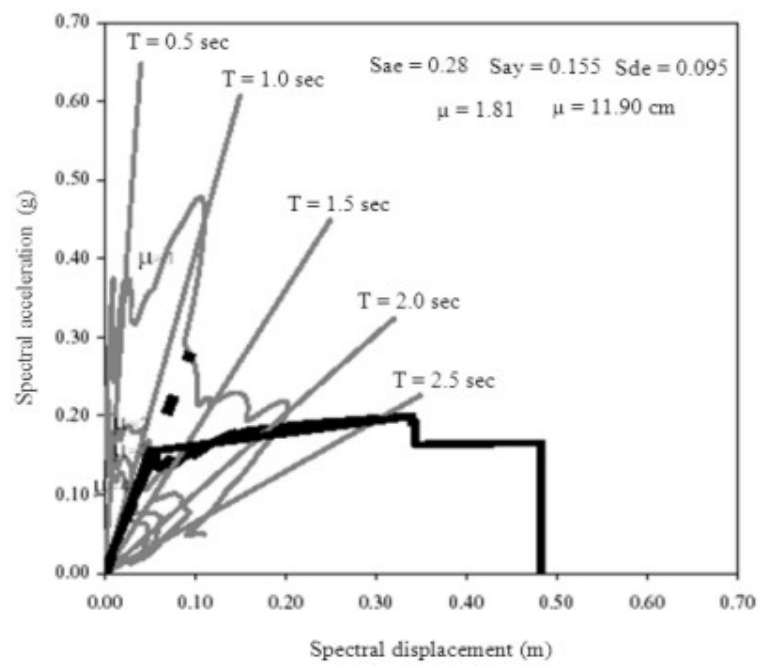

Fig. 25: Comparison of capacity and demand spectrum for IDF under KC52sba with a design earthquake by IDDM by Fajfar

Table 8: Comparison of displacement demand for various frames by IDDM by Chopra and Goel under a suite of ground motion records with a design earthquake

\begin{tabular}{|c|c|c|c|c|c|c|c|c|}
\hline \multirow[b]{3}{*}{ EQ. } & \multicolumn{8}{|c|}{ Displacement demand $(\mathrm{cm})$} \\
\hline & \multicolumn{2}{|l|}{ ODF } & \multicolumn{2}{|c|}{ IDF } & \multicolumn{2}{|c|}{ SDF } & \multicolumn{2}{|l|}{ GLD } \\
\hline & IDDM & NTHA & IDDM & NTHA & IDDM & NTHA & IDDM & NTHA \\
\hline ELC40 & 10.3 & 6.2 & 6.3 & 6.2 & 6.3 & 6.1 & 6.4 & 6.1 \\
\hline SBK & 12.2 & 16.9 & 10.2 & 15.3 & 10.1 & 13.9 & 10.0 & 15.6 \\
\hline LP89stg & 10.3 & 7.9 & 6.9 & 7.9 & 6.8 & 7.8 & 7.4 & 7.8 \\
\hline LP89cfh & 14.0 & 13.0 & 9.4 & 12.8 & 9.3 & 12.8 & 9.3 & 13.1 \\
\hline KC52sba & 11.5 & 14.8 & 8.2 & 13.5 & 8.1 & 13.3 & 8.1 & 14.5 \\
\hline Average & 11.6 & 11.8 & 8.2 & 11.2 & 8.1 & 10.8 & 8.2 & 11.8 \\
\hline
\end{tabular}

demands at the performance point evaluations are given in Table 8. All frames are predicted performance to be the immediate occupancy performance level when subjected to a design earthquake.

Fajfar (2000) presented the intersection of the radia line corresponding to the elastic period of the idealized bilinear system, $\mathrm{T}^{*}$ with the elastic demand spectrum. As an example, Fig. 25 presents theperformance point evaluation of IDF subjected to KC52sba with a design earthquake. At the performance point under a suite of record ground motions with a design earthquake, the average ductilities for ODF, IDF, SDF and GLD are 1.26, 1.63, 1.75 and 1.80, respectively. The displacement demands at the performance point evaluations are given in Table 9. Table 9 shows that performances of all frames are predicted to be the immediate occupancy performance level when subjected to a design earthquake.

Comparisons of performance points for various frames for all five selected ground motions with a design earthquake are indicated on Capacity spectrum
Table 9: Comparison of displacement demand for various frames by IDDM by Fajfar under a suite of ground motion records with a design earthquake

\begin{tabular}{lrrrrrrrr}
\hline \multicolumn{7}{c}{ Displacement demand (cm.) } \\
& ODF & \multicolumn{3}{c}{ IDF } & SDF & GLD & \\
EQ. & IDDM & NTHA & IDDM & NTHA & IDDM & NTHA & IDDM & NTHA \\
\hline ELC40 & 6.4 & 6.2 & 6.3 & 6.2 & 6.2 & 6.1 & 6.2 & 6.1 \\
SBK & 15.4 & 16.9 & 15.0 & 15.3 & 14.8 & 13.9 & 14.9 & 15.6 \\
LP89stg & 7.7 & 7.9 & 7.4 & 7.9 & 7.4 & 7.8 & 7.7 & 7.8 \\
LP89cfh & 16.7 & 13.0 & 11.3 & 12.8 & 11.1 & 12.8 & 14.9 & 13.1 \\
KC52sba & 12.6 & 14.8 & 11.9 & 13.5 & 11.7 & 13.3 & 11.8 & 14.5 \\
Average & 11.7 & 11.8 & 10.4 & 11.2 & 10.2 & 10.8 & 11.1 & 11.8 \\
\hline
\end{tabular}

and Inelastic Demand Diagram Methods. SAP2000 is the only program that can be used to generate the capacity curve and demand curve for performance evaluation according to CSM. These procedures are the advantage to give the engineer the opportunity to visualize the relationship between demand and capacity spectra. When evaluation methods are compared, the results indicate that the ductility and displacement demands estimated by CSM in ATC-40 and IDDM are different. In fact, the demand obtained from CSM is represented by elastic response spectra for a viscous damping ratio while in the IDDM, the demand is represented by inelastic response spectra for a ductility levels.

IDDM may be regarded as more accurate than the CSM because it makes use of a certain inelastic demand spectra rather than equivalent inelastic spectra. The results show that with a design earthquake these frame buildings in Bangkok are predicted to just achieve the Immediate Occupancy (IO) performance level. The results also indicate that these frame buildings will not collapse when they are subjected to the intensity earthquake ground motions according to Bangkok design spectrum level.

For comparisons the IDF response when subjected to levels of intensity of design spectrum was evaluated. Performance points according to a design and double design earthquakes were determined. At the performance points for IDF under a suite of ground motions by CSM, IDDM by Chopra and Goel and IDDM by Fajfar at a design earthquake showed average ductilities of $1.21,1.30$ and 1.63 , respectively and at double design earthquake are 1.37, 2.03 and 3.46, respectively. The average displacement demands at the performance point evaluations are given in Table 10 for double design earthquake. In conclusion, the results indicate that these frame buildings will not collapse when they are subjected to the design and double design earthquakes.

According to the study, the failure criteria was assumed to have collapsed if the local drift ratio exceed of $3 \%, 2.5 \%, 2 \%$ and $1 \%$ for SDF, IDF, ODF and GLD, 
Am. J. Engg. \& Applied Sci., 4 (1): 17-36, 2011

Table 10: Comparison of displacement demand for IDF at double design earthquake resulting from various methods under a suite of ground motion records

\begin{tabular}{lrcl}
\hline & Displacement demand $(\mathrm{cm})$. & \\
& - & $\begin{array}{l}\text { IDDM by } \\
\text { Chopra and Goel }\end{array}$ & $\begin{array}{l}\text { IDDM by } \\
\text { Fajfar }\end{array}$ \\
\hline ELC40 & CSM & 8.8 & 13.8 \\
SBK & 9.3 & 18.8 & 30.0 \\
LP89stg & 13.3 & 9.8 & 13.8 \\
LP89cfh & 15.0 & 11.3 & 22.0 \\
KC52sba & 16.2 & 15.0 & 22.5 \\
Average & 24.8 & 12.7 & 20.6 \\
NTHA (average $=16.3)$ & 15.7 & & \\
\hline
\end{tabular}

Table 11: Comparison of PGA at failure state for various frames by CSM under a suite of ground motion records

\begin{tabular}{lllll}
\hline \multicolumn{5}{c}{ PGA } \\
EQ. & ODF (g) & IDF (g) & SDF (g) & GLD (g) \\
\hline ELC40 & 0.66 & 0.64 & 0.55 & 0.39 \\
SBK & 0.55 & 0.72 & 0.88 & 0.33 \\
LP89stg & 0.53 & 0.65 & 0.88 & 0.29 \\
LP89cfh & 0.44 & 0.50 & 0.68 & 0.26 \\
KC52sba & 0.28 & 0.45 & 0.81 & 0.18 \\
Average & 0.50 & 0.60 & 0.76 & 0.29 \\
\hline
\end{tabular}

Table 12: Comparison of displacement demand at failure state for various frames by CSM under a suite of ground motion records

\begin{tabular}{lllll}
\multicolumn{5}{c}{ records } \\
& \multicolumn{3}{l}{ Displacement demand (cm.) } & \\
\cline { 2 - 5 } EQ. & ODF & IDF & SDF & GLD \\
\hline ELC40 & 21.1 & 20.6 & 17.5 & 10.7 \\
SBK & 22.5 & 28.0 & 33.3 & 11.3 \\
LP89stg & 22.8 & 28.1 & 29.8 & 11.8 \\
LP89cfh & 22.5 & 28.0 & 34.3 & 11.1 \\
KC52sba & 21.2 & 27.7 & 32.3 & 10.9 \\
Average & 22.0 & 26.5 & 29.4 & 11.1 \\
\hline
\end{tabular}

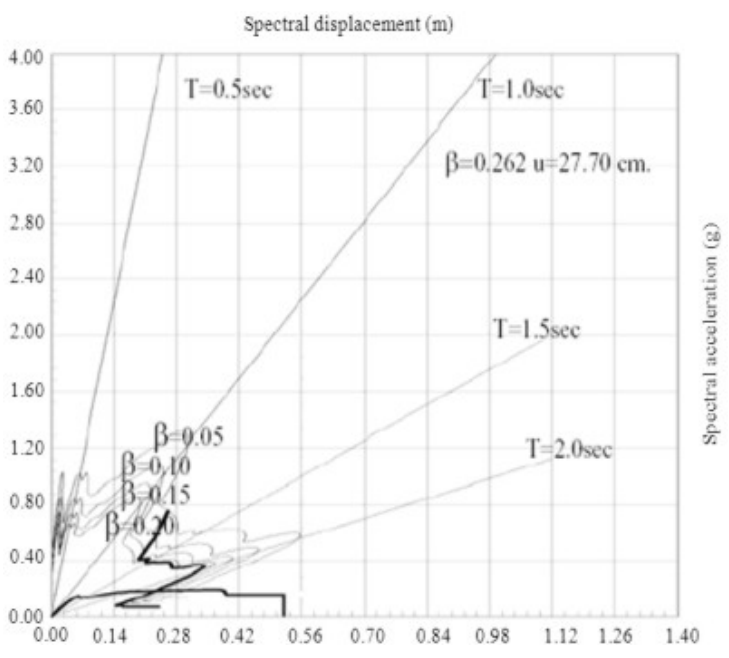

Fig. 26: Comparison of capacity and demand spectrum at failure state for IDF under KC52sba by CSM in ATC-40 respectively. As an example, Fig. 26 presents the performance point evaluation at failure state of IDF subjected to KC52sba. The average ductilities at failure state for ODF, IDF, SDF and GLD are 1.26, 1.48, 1.53 and 1.15 , respectively. The average PGA at failure state for ODF, IDF, SDF and GLD are 0.50, 0.60, 0.76 and $0.29 \mathrm{~g}$, respectively (Table 11). Moreover, for the failure state of GLD with volumetric ratio of horizontal confinement within joint panel less than 0.003 , the average PGA is $0.15 \mathrm{~g}$. Table 12 shows the displacement demands at the performance point at failure state of various frames by CSM.

\section{CONCLUSION}

This study is focused on the effect on cost estimates and the investigation of seismic performance for nine-story reinforced concrete moment resisting frames with various ductilities by the nonlinear static analyses and nonlinear dynamic analysis under seismic loadings in Bangkok according to the newly proposed seismic specifications of Thailand (DPT 1302-52). These structures were designed and detailed in accordance with provisions of UBC 1997 and of DPT standard 1301-50 so that they can be representative of the Ordinary (ODF), Intermediate (IDF), Special (SDF) ductile frames with a modification factor of 3,5 and 8 , respectively compared with Gravity Load Designed frames (GLD). Based on large amount of information obtained in this study, the following conclusions are drawn:

- For effect on cost estimates under the new code, the Ordinary Ductile Frame (ODF) is the most expensive among the Ordinary (ODF), Intermediate (IDF) and Special (SDF) ductile frames. It was also found that the costs of special and intermediate ductile frames are quite similar in a low seismic zone because of the requirement for strong column-weak beam in SDF design. SDF required less main reinforcement but more transverse reinforcement than Intermediate (IDF) and ordinary (ODF) ductile frames

- The Special Ductile frame (SDF) with a modification factor of 8 is more ductile than the Ordinary Ductile Frame (ODF) with a modification factor of 3. However, the strength of Special Ductile Frame (SDF) is less than that of the Ordinary Ductile Frame (ODF). For inelastic designs, the Special Ductile Frame (SDF) with a modification factor of decreases stiffness and increases deflection of structures because energy under this ductile frame is dissipated 
- The results prove that the profiles of floor displacement and local drift ratio of Modal Pushover (MPA) and Nonlinear Time History Analysis (NTHA) are similar. Compared to responses using Nonlinear Time History Analysis (NTHA) during a suite of ground motion records, local drift ratios from Modal Pushover Analysis (MPA) are overestimated at lower floors and quite similar at upper floors For Ordinary (ODF), Intermediate (IDF) and Special Ductile (SDF) frames. In addition, the results for each ground motion record exhibit theirs own particularities, corresponded to frequency content

- As far as the effect of ductility class is concerned, Special (SDF), Intermediate (IDF) and Ordinary (ODF) ductility classes are to perform satisfactorily during a design earthquake. The local drift of the frame building does not exceed the limits of 2-3\% of story height. Although SDF was designed for five-eighths of the value of the designed lateral load of IDF, all components of SDF had to satisfy the applicable special proportioning and detailing requirement to have a level of toughness adequate enabling the structure to perform well during a design earthquake. It demonstrated the successful application of the strong column weak beam implemented in the capacity design

- When a suite of ground motion records were normalized by scaling to an intensity of $5 \%$ of the damped elastic design spectrum, floor displacement and local drift ratio by modal pushover and nonlinear dynamic procedures are

slightly different from scaling such that the value of 5\% damped spectral acceleration at the fundamental period matches the design spectrum. However, story drift and floor displacement profiles by the two methods are quite similar. Local drift ratios from modal pushover analysis are overestimated at lower floors and quite equal at upper floors for frames of all ductility classes compared to responses using nonlinear dynamic analysis. The reason for this is that the nonlinear time history analysis assumed a hysteretic moment rotation relationship. The model can absorb energy through hysteretic damping

- When subjected to a design and double design earthquakes as the collapse prevention, the seismic damages resulting from a design earthquake are less than those to double design earthquake. However, the local drift ratios of IDF do not exceed the failure limits of 2-3\% of storey height. According to this study, deformations of structures are not critical under a design and double design earthquakes. However, they may cause the structures to damage
- When subjected to a design earthquake by Modal Pushover (MPA) and Nonlinear Time History (NTHA) analyses, these frame buildings are estimated to just achieve the Immediate Occupancy (IO) performance level. The results also indicate that these frame buildings will be able to withstand the intensity of earthquake ground motion according to Bangkok design spectrum. Various frames will be damaged, however, if the structures are subjected to severe earthquake ground motion. Structures are assumed to have collapsed if the local drift ratios exceed of 2-3\%

- The various frames are assumed to have collapsed if the local drift exceed of 3, 2.5, 2 and $1 \%$ for SDF, IDF, ODF and GLD, respectively. The average PGA for the failure state is $0.76,0.60,0.50$ and $0.29 \mathrm{~g}$, respectively. Moreover, for the failure state of GLD with volumetric ratio of horizontal confinement within joint panel less than 0.003 , the average PGA is only $0.15 \mathrm{~g}$

- Performance-based designs evaluated under a suite of ground motion records from a design earthquake show that predictions from the Capacity Spectrum Method (CSM) in ATC-40, procedure B are different than the Inelastic Demand Diagram Method (IDDM) by Chopra and Goel, IDDM by Fajfar and NTHA. The demand obtained from

- CSM is represented by elastic response spectra for a viscous damping ratio while for the IDDM, the demand is represented by inelastic response spectra for a ductility level. IDDM may be regarded as more accurate than the CSM because it makes use of a certain inelastic demand spectrum rather than equivalent inelastic spectra. These analyses provide an advantage to the engineer allowing the visualization the relationship between demand and capacity spectra

\section{ACKNOWLEDGEMENT}

The authors would like to greatly acknowledge the Thailand Research Fund (TRF) for providing the partially financial support for this study under Grant Number RDG5130021. The authors would also like to sincerely acknowledge Assoc. Prof. Dr. Pennung Warnitchai of Asia Institute of Technology for being the head of this research group fund and valuable advice. This study was also partially supported by the National Research University Project of Thailand Office of Higher Education Commission. The valuable comments of the anonymous reviewers of the paper are also acknowledged. 
Am. J. Engg. \& Applied Sci., 4 (1): 17-36, 2011

\section{REFERENCES}

ACI, 1995. Building Code Requirements for Structural Concrete (ACI 318-95). ACI Committee 318, American Concrete Institute. 6th Edn., Farmington Hills, Michigan, ISBN:0-89312-144-4, pp: 759.

ASCE, 2005. Minimum Design Loads for Buildings and Other Structures (ASCE7-05). 1st Edn., American Society of Civil Engineers, USA., ISBN: 0-7844-0831-9, pp: 424.

ATC, 1996. Seismic Evaluation and Retrofit of Concrete Building. ATC-40 Report No. SSC96-01, Applied Technology Council, Redwood City, California, pp: 254.

Boonyapinyo, V., P. Warnichai and N. Intaboot, 2006. Seismic capacity evaluation of post-tensioned concrete slab column frame building by pushover analysis. J. Sci. Technol. Songklanakarin, 28: 1033-1048.

Choopool, N., 2010. Seismic Performance Evaluaton of Reinforced Concrete Moment Resisting Frames with Various Ductility in Low to Moderate Seismic Zones. Ph.D. Eng. dissertation, Thammasat University.

Chopra, A., 2007.Dynamics of Structures: Theory and Applications to Earthquake Engineering. 3rd Edn., Prentice Hall, Englewood Cliffs, New Jersey. ISBN 0-13-156174-X, pp: 876.

Chopra, A.K. and R.K. Goel, 1999. Capacity-demanddiagram methods based on inelastic design spectrum. Earthquake Spectra, 15: 637-666. DOI: 10.1193/1.1586065

Chopra, A.K. and R.K. Goel, 2002. A modal pushover analysis procedure for estimating seismic demands for buildings. Earthquake Engineer. Struc. Dynamic, 31: 561-582, DOI: 10.1002/eqe.144

DPT, 2007. Additional Standard for Building Design under Seismic Load (DPT 1301-50). Department of Public works and Town and Country Planning, ISBN: 978-974-458-162-4, pp: 19.

DPT, 2009. Standard for Building Design under Seismic Load (DPT 1302-52). Department of Public works and Town and Country Planning ISBN: 978-974-458-276-8, pp: 113.

Elnashai, A.S. and A.M. Mwafy, 2001. Static pushover versus dynamic collapse analysis of RC buildings. Engineer. Struc., 23: 407-424. DOI: 10.1016/S0141-0296(00)00068-7
Fajfar, P., 2000. A nonlinear analysis method for performance based seismic design. Earthquake Spectra, 16: 573-592. DOI: 10.1193/1.1586128

FEMA NEHRP, 1997. Guidelines for the Seismic Rehabilitation of Building and NEHRP Commentary on the Guidelines for the Seismic Rehabilitation of Building. Report No. FEMA273/274, Federal Emergency Management Agency, Washington D.C, p.435.

Kiattivisanchai, S., 2001. Evaluation of Seismic Performance of an Existing Medium-Rise Reinforced Concrete Frame Building in Bangkok. M. Eng. Thesis, Thesis No. ST-01-11, Asian Institute of Technology

Kunnath, S.K. and E. Kalkan, 2007. Assessment of current nonlinear static procedures for seismic evaluation of buildings. Engineer. Struc., 29: 305-316. DOI: 10.1016/engstruct.2006.04.012

Kunnath, S.K., A.M. Reinhorn and Y.J. Park, 1990. Analytical modeling of inelastic seismic response of R/C structures. J. Struc. Engineer., 116: 996-1017. DOI: 10.1061/(ASCE)/07339445(1990)116:4(996)

Lukkunaprasit, P., 2001. Seismic Design of Structure. The Fourth Seminar on Seismic Design. 1st Edn., Engineering Institute of Thailand, pp: 162-201.

Pessiki, P., C. Conley, R. White and P. Gergely, 1990. Seismic behavior of the beam-column connection region in lightly-reinforced concrete frame structures. Proceed. U.S. Nat. Conf. Earthquake Engineer., 2: 707-716.

SAP2000, 2000. Integrated Finite Element Analysis and Design of Structure: Analysis Reference. Computers and Structures,1st Edn., Inc., Berkeley, California, pp: 154.

Seneviratna, G.D.P.K. and H. Krawinkler, 1997. Evaluation of Inelastic MDOF Effects for Seismic Design. John A. Blume Earthquake Engineering Center, Standford University, Report No.120, pp: 177.

UBC, 1997. Uniform Building Code, Structural Engineering Design Provisions (UBC1997). International Conference of Building Officials (ICBO), ISBN: 0-8247-5934-6, pp: 893.

Warnitchai, P. and C. Sangarayakul, 2000. Seismic Hazard in Bangkok Due to Long-Distance Earthquakes. Proceeding of the 11th World Conference on Earthquake Engineering, (WCEE'2000), Auckland, New Zealand, pp: 11. 